This item was submitted to Loughborough's Research Repository by the author.

Items in Figshare are protected by copyright, with all rights reserved, unless otherwise indicated.

\title{
Decomposing the growth of the high-skilled wage premium in an advanced economy open to trade
}

\section{PLEASE CITE THE PUBLISHED VERSION}

https://doi.org/10.1016/j.qref.2019.02.007

\section{PUBLISHER}

(c) Board of Trustees of the University of Illinois. Published by Elsevier Inc.

\section{VERSION}

AM (Accepted Manuscript)

\section{PUBLISHER STATEMENT}

This paper was accepted for publication in the journal Quarterly Review of Economics and Finance and the definitive published version is available at https://doi.org/10.1016/j.qref.2019.02.007

\section{LICENCE}

CC BY-NC-ND 4.0

\section{REPOSITORY RECORD}

Edwards, Huw, and Matthias Luecke. 2019. "Decomposing the Growth of the High-skilled Wage Premium in an Advanced Economy Open to Trade". Loughborough University. https://hdl.handle.net/2134/37135. 


\title{
Decomposing the Growth of the High-Skilled Wage Premium in an Advanced Economy open to Trade
}

\author{
T. Huw Edwards* and Matthias Lücke ${ }^{\dagger}$
}

\begin{abstract}
We use a double-calibrated general equilibrium model to decompose the growth of the high-skilled wage premium in the UK from 1979 to 2000 into a range of potential contributory factors. This structural approach ensures that the model used is consistent with both price and quantity data simultaneously, and allows us to investigate a wide range of plausible parameter values. We find that the small observed rise in the skill premium is the net outcome of a set of opposing effects, some of which are large. In particular, the negative effect on the skill premium from the rising supply of skilled labour is mostly offset by the factor bias of technical change in favour of skilled labour. To this extent our work supports previous labour-market based studies, but is novel in showing that these are consistent with trade price and volume changes in a general equilibrium framework. If we assume a production technology dominated by capital-skill complementarity, the fall in capital prices (positive effect on the skill premium) and the sector bias of technical change in favour of unskilled-labour-intensive sectors (negative effect) also become quantitatively important. The impact of international trade and consumer preferences on the skill premium is mostly positive, and while not large compared to the role of factor bias, it is still significant as a proportion of to the net change in the wage premium. We conclude that a structural model such as ours provides robust insights into the processes that drive the skill premium. At the same time, while we treat the rise in the supply of skilled labour as exogenous, future research might usefully aim to endogenize skill acquisition decisions and labour market policies with a more fully dynamic modelling technique.
\end{abstract}

JEL Classifications: C68, F16, O4.

Keywords: General equilibrium, wage inequality, trade.

\footnotetext{
${ }^{*}$ Loughborough University, UK.

${ }^{\dagger}$ Institut für Weltwirtschaft, Kiel, Germany.
} 


\section{Introduction}

One motivation for the current trade wars and opposition to international integration (Becker et al., 2016; Wood, 2018 ) is the rise in wage inequality in many advanced economies over recent decades, at the same time that trade with poorer countries also increased. ${ }^{1}$ In much of the literature from the 1990s onwards, this has led to an approach which Chusseau et al. (2008) term 'find the culprit', asking whether there is a strong causal relationship from trade liberalization to trade. Against this, most of the earlier studies found relatively little impact from trade and tended therefore to attribute growing wage inequality to skill-biased technical progress (SBTP). Subsequent studies have shown that this view needs to be tempered: first, because there are more than two potential causal factors at play (we list the main ones below); and second, because changes in prices or technology have indirect effects which need to be handled consistently. ${ }^{2}$

In this paper, we suggest that understanding the linkages between the various possible causes of rising inequality requires relatively sophisticated, structural tools for decomposition. Consequently, we recommend and demonstrate the use of a multi-equation computable general equilibrium (CGE) model that is calibrated simultaneously upon price and output data in two (or more) years and allows the changes between the years to be broken down according to several contributory factors by means of a set of iterated counterfactual simulations. This approach is not entirely novel: while most of the literature has applied single-equation approaches (which are flawed in our view, as we discuss below), several papers have used general equilibrium simulations: e.g. (Leamer, 1998a; Bontout and Jean, 2000; DeSantis, 2003; Atolia and Kurokawa, 2016). However, only a few relatively simple, schematic models (Abrego and Whalley, 2003; Edwards and Whalley, 2007) have used calibration on both prices and quantities in both start and end years.

This is unfortunate because, once a set of assumed elasticities (drawn from the literature elsewhere) is applied, this approach is capable of identifying simultaneous changes in trade, taste, and several technological parameters. By contrast, most of the existing literature cannot do this, or does so only by relatively clumsy means. Hence, in this paper, we take the dual-calibrated, multi-equation CGE approach and extend it to a somewhat larger model to carry out decomposition analysis. To our knowledge, the use of iterated simulations is new in the trade and wages literature and avoids the usual problem of decomposition analysis producing unattributed 'joint effects'. Our decomposition approach shows that the popular analyses, which focus on identifying a single cause, are over-simplistic. In particular, the observed change in inequality is the net result of a several distinct factors that work in opposite directions. Hence, contrary to what many previous studies imply, finding that a single factor had a large impact on inequality does not preclude a significant role for other factors. In particular, this indicates that, while the strongest influences on inequality (when calibrated to the data) are capital cheapening and factor biased technical progress, this does not rule out a significant role for

\footnotetext{
${ }^{1}$ More recently, unskilled migration has increasingly been mentioned.

${ }^{2}$ Chusseau et al. (2008) discuss the literature on how traded prices may affect intermediate inputs and hence the demand for capital as well as skilled and unskilled labour.
} 
trade and sector biased technology.

In the following section 2, we review the evolution of UK wage inequality over the last half century and discuss possible contributing factors and how they have been addressed in the previous literature. In section 3 we outline the structure of our dual-calibrated CGE model and our micro-consistent database, while in section 4 we present the results of our decomposition. Section 5 concludes.

\section{Changes in UK wage inequality and possible causal factors}

Income inequality began to rise in the UK just before 1980 (Figure 1, below). The Gini coefficient reaches a relative plateau around 1990, while the other two measures continue to rise until 2000. Since then, they have remained fairly constant, with a slight peak before the 2008 crash. In our decomposition analysis, we therefore focus on the period from 1979 to 2000 .

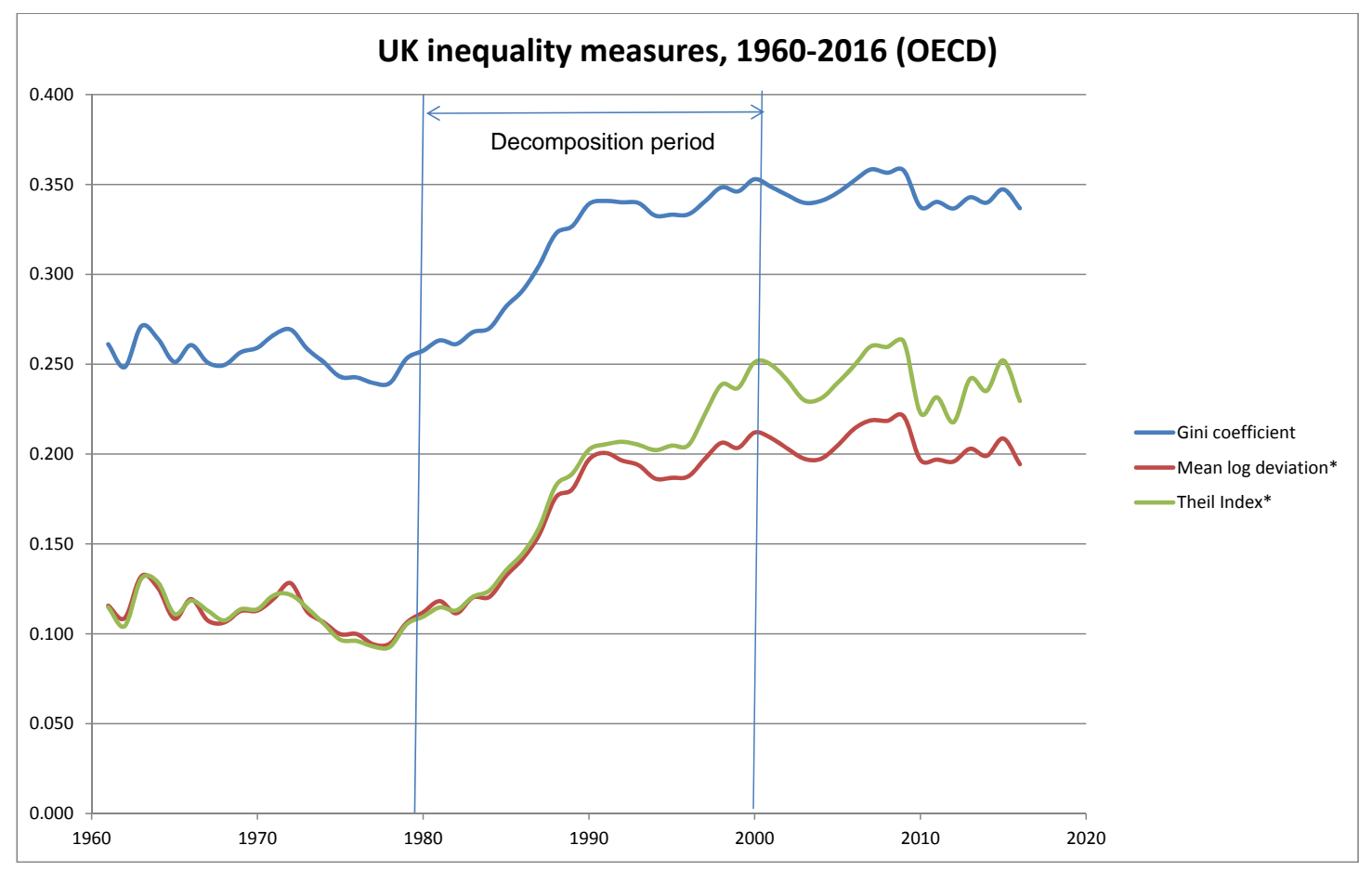

Figure 1: Income inequality measures for the United Kingdom, 1960-2016. 
Table 1: Skilled and unskilled wages in real terms, derived from UK Labour Force Survey.

\begin{tabular}{lccccc}
\hline Hourly wage 1982 prices & Year & Unskilled & Skilled & Ratio & Change in ratio \\
& $\mathbf{1 9 7 9}$ & 4.87 & 7.232 & 1.48 & na \\
& $\mathbf{2 0 0 0}$ & 6.81 & 10.94 & 1.60 & 1.12 \\
\hline
\end{tabular}

For our decomposition analysis, we need to focus on a single inequality measure. Furthermore, due to data availability, we concentrate on just one aspect of the inequality story: the gap between mean wages of 'skilled' (white collar) and 'unskilled' (blue collar) workers. ${ }^{3}$ From 1979 to 2000, the skilled/unskilled wage ratio widened by 12 percent (Table 1). Although this increase in the skilled wage premium is smaller than in some other inequality measures (particularly at the top of the income scale), this is the measure on which the trade and wages debate has focused (plus we have have reliable data from the Labour Force Survey). ${ }^{4}$

Having defined the object of our decomposition - the widening skilled/unskilled wage premium in the UK between 1979 and 2000, we now consider a fuller list of potential causative factors against the background of the existing literature. We discuss in more detail in Section 3 below how we treat, and measure, each factor in our own analysis.

1. Trade, or more usually North-South trade (NST). In the simple neoclassical Heckscher-Ohlin-Samuelson (HOS) model of trade, the Stolper-Samuelson theorem (Stolper and Samuelson, 1941) describes the relationship between factor prices and traded goods prices. While there are serious problems in reconciling the simpler versions of the HOS model with actual trade (notably the presence of intra-industry trade), this does not stop important studies - notably Leamer (1998b) - from referring to 'Stolper Samuelson effects'. In richer models, traded goods prices affect wages via their effect upon producer prices within a country. Even when this relationship is weakened by imperfect substitution between imported and domestic goods, as in the Armington model (Abrego and Whalley, 2003), some form of Stolper-Samuelson effect will occur when trade is liberalized with economies that are more abundant in unskilled labour. Interestingly, income inequality in the UK increased sharply during the 1980s (Figure 1), whereas imports from China (in particular) surged around 2000, from which date inequality measures were actually flat.

One concern in much of the previous literature (notably Lawrence and Slaughter (1993)) is that, in the 1980s and 1990s, traded prices of skill-intensive goods probably fell, on most measures, compared to unskilledintensive goods. Hence, according to the Stolper-Samuelson logic, the wage premium should have declined rather than increased. However, import shares in consumption tell a different story, as we discuss in section 3 below. In particular, when we assume a low Armington trade elasticity, we find a substantial inward shift in the

\footnotetext{
${ }^{3}$ Following Piketty (2014), attention has recently focused on the top percentile of the income distribution - 'the 1 percent' - but here we consider the distribution within the remaining 99 per cent, which has also widened. Note that this debate differs from that over the relative capital and labour shares of income, which has been the focus of Autor et al. (2017) and Grossman et al. (2017), among others.

${ }^{4}$ We acknowledge that there are potential drawbacks to using mean values of the two groups (and indeed that white collar workers, in particular, are not uniformly skilled). Some recent studies use assignment models to explain both within- and between-industry wage distributions (Costinot and Vogel (2015), Burstein and Vogel (2017)). However, there are still many complexities involved in adopting this approach (such as the treatment of flows of skill types between industries). Therefore, we pursue a more orthodox approach.
} 
demand for UK produce compared to imports in the unskilled-intensive sector. This finding needs to be considered in the light of the literature following Anderson and van Wincoop (2004) where, in a gravity/Armington trade setup, trade costs are estimated to be large and variable over time. In this setup, a rising Armington import share in unskilled-intensive sectors implies that the implicit trade costs (which may reflect non-tariff barriers as well as regulatory protection) were falling relatively fast in these sectors.

2. Skill-biased technical progress (SBTP). As the literature on SBTP has developed, it has become apparent that there are two separate aspects of SBTP that both need consideration (Jones (1965); Jones (2000)):

a) The factor bias of technical progress represents changing factor input ratios (capital, skilled labour, unskilled labour) within an industry, after correcting for factor price changes. Much of the literature on SBTP has argued that the skilled to unskilled input ratio has increased within many industries while less unskilled labour was used. This observation may partly reflect computerization and mechanization, which it is argued require more of certain types of skilled worker to carry out (Autor and Dorn (2013), Autor et al. (2017)), while at the same time replacing more 'routine tasks', which can be automated. In terms of the trade, labour and productivity literature, this effect is termed 'factor bias', and in technical terms it should be compared to Hicksneutral technical progress (i.e. technical progress with no factor bias) under which industry output industry grows while the various factor input ratios are unchanged after controlling for changes in factor prices. Hence, if we write $Y=A \cdot f(K, U, S)$, where $K, U$ and $S$ are capital, skilled and unskilled inputs into an industry, then Hicks-neutral technical progress is a change in the scale parameter $A$ only.

b) The sector bias of technical progress has been raised as a possible contributory factor: Total factor productivity may grow faster in some industries than in others. In this case, technical progress may alter wages in an open economy, not just by altering ratios of inputs within each industry, or by displacing certain workers, but by altering the relative production costs of different industries. In other words, even if technical progress within each sector is Hicks-neutral, the general equilibrium effect of technical progress on wages may display a skill bias if technical progress proceeds faster in skill-intensive sectors, as Haskel and Slaughter (2001) and Haskel and Slaughter (2002) demonstrate with data on computerization rates.

Thus, in HOS theory, faster technical progress in skill-intensive sectors affects trade specialization in a similar way to falling relative prices for unskilled-intensive goods. Indeed, it may be seen as a solution to what Kurokawa (2014) terms the 'price-wage anomaly', based on the observation (Lawrence and Slaughter (1993)) of falling relative prices of skill-intensive goods in the US: With relatively rapid technical progress, these sectors may actually have become more competitive. Hence, any discussion of technical progress that seeks to distinguish its impact from the effects of North-South trade should consider both the sector and the factor bias.

3. Capital cheapening, combined with capital-skill complementarity. A number of studies, from Griliches (1969) onwards, have indicated that installing more physical capital tends to increase the demand for skilled workers to operate complex equipment, while displacing unskilled workers. This became partic- 
ularly apparent with computerization. While Krusell et al. (2000) is often regarded as the seminal study on capital-skill complementarity, we would also mention Winchester and Greenaway (2007).

The potential impact of capital-skill complementarity is large because capital goods have become much cheaper since the late 1970s: Bank of England studies (Bakhshi and Thompson (2002), Baumann and Price (2007)) indicate a near halving of the business investment deflator compared to the GDP deflator, and a rise, starting around 1983, in the business investment/GDP ratio in constant 1995 prices. The causes of the decline in the deflator can be split about equally into a fall in the relative price of investment goods - reflecting both technical progress in producing investment goods and the effects of a strong pound in the later part of our period - and a reduction in real interest rates and equity risk premia as well as some benefits from credit market liberalization.

We note that, where technical progress is embodied in new machinery and equipment, it is a moot point whether technical progress that favours skilled over unskilled labour should be interpreted as representing capital cheapening or factor bias.

4. Taste parameters. Hillberry et al. (2005) show that changing consumer preference parameters are important in 'fitting' general equilibrium models of trade. We find some evidence of a shift in consumer demand towards more skill-intensive products, which tends to increase the skill premium.

5. Changes in intermediate input parameters. Similar to changes in taste parameters, outsourcing (i.e. increased purchases of intermediates) may affect labor demand and wage premia - for example, (Anderton and Brenton, 1999; Feenstra and Hanson, 1996)). Of course, outsourcing is not entirely exogenous (Chusseau et al., 2008; Kurokawa, 2014) and we argue that it should only be seen as a causal factor to the extent that the share of purchased inputs shifts after correcting for the effects of changing input prices. ${ }^{5}$. This again is an important argument for a general equilibrium approach, which we adopt. In particular, we use a non-Leontief structure to incorporate intermediate inputs into the production function so that purchased input shares will respond to changes in traded goods prices (effectively endogenizing outsourcing).

6. Labour supply changes. Unless the economy faces totally flat traded goods prices (and lies within the 'cone of diversification'), a rise in the relative supply of skilled labour should depress the skill premium. Consequently, many of the labour-market-based approaches to inequality (Katz and Murphy (1992) is a classic example) analyze the evolution of the skill premium in terms of changes in skill supply versus SBTP. ${ }^{6}$ Over the period concerned, the relative supply of white collar to blue collar workers nearly doubled, although there must be questions about the endogeneity of the supply of skills, given the rise in the wage premium. Schematic, HOS-based analyses see little role for labour supply changes, other than in setting the boundaries of the cone of diversification within which changes in relative factor supplies affect the output mix but not factor prices.

\footnotetext{
${ }^{5}$ Even Krugman (2008) partially reversed his earlier judgment that trade had had little effect on US relative wages, based upon arguments about the composition of trade within industries

${ }^{6}$ Acemoglu (2002) incorporates a discussion of capital-skill complementarity in this approach. He also discusses the role of trade, but views it as tangential.
} 
However, previous studies, e.g. Edwards and Whalley (2007), have shown that factor price equalization under these assumptions is not robust. Our present analysis confirms the view of Katz and Murphy (1992) and others that labour force upskilling and SBTP/capital cheapening are the primary drivers of the skill premium, given a general equilibrium setting and a wide variety of parameter assumptions. Of course, in any decomposition analysis, there is an issue of which factors should be considered exogenous. The relative supply of skills probably responds partly to the wage premium, while Acemoglu (2002) argues strongly that SBTP may itself be endogenous, responding with a lag to relative wages (although we would argue that in a small open economy such as the UK we may sensibly treat technology as exogenous).

Other possible causes of the rise in the skill premium include changes in wage bargaining (the 1980s saw a sharp fall in unionization) and declining subsidies to state-owned industries (this could be interpreted as a reduction in protection where output is potentially tradeable). Alternative arguments that SBTC may be partly endogenous follow from Sampson (2014) and Harrigan and Reshef (2015) as well as Edwards and Perroni (2014): the former argue that Melitz-style firm selection is biased in favour of firms that employ more skilled workers, while the latter argue that technological progress, induced by trade, displaces unskilled workers. This is in line with earlier work on variety and skill complementarity (Kurokawa, 2014). These arguments require further research, but are beyond the scope of this study.

Having set out the object of our decomposition and the possible causal factors, we now review the simpler alternatives to our structural, dual-calibrated approach. The literature based upon reduced form analysis is sizable and has generated considerable controversy. "Blame" for the rise in the skill premium is attributed, solely or partly, to rising import volumes from developing countries (Wood, 1994), falling trade prices (Leamer, 1998b), skill-biased technical change (numerous studies), unskilled immigration, sector-biased technical change favouring skill-intensive industries (Haskel and Slaughter, 2002), falling capital prices combined with capitalskill complementarity (Krusell et al., 2000) and outsourcing (Feenstra and Hanson, 1996; Anderton and Brenton, 1999).

With the single-equation approach, there are two main decomposition methodologies. First, a number of studies (Borjas et al., 1992; Murphy and F.Welch, 1989; Katz and Murphy, 1992; Wood, 1994) have simply fallen back on an aggregate macroeconomic production function with fairly ad hoc adjustments for job displacement. ${ }^{7}$ This factor contents approach involves, first, deriving the changes in net imports by sector; second, weighting these changes by skilled and unskilled employment in each sector; and third, combining them with an aggregate production function to estimate aggregate skilled and unskilled labour demand curves and derive the implied changes in market clearing wages. Having thus estimated the contribution of 'trade', the contribution of the other major factor, 'technology', is usually derived as a residual due to the lack of specific data. Some studies also account for demographics and immigration.

The second major approach to decomposition is based on Stolper and Samuelson (1941) and has, at first

\footnotetext{
${ }^{7}$ Wood (2018) also surveys this literature and concludes that the results are inconclusive.
} 
sight, a stronger theoretical foundation. Given correct information on the structure of an economy, it is in principle possible to develop a reduced form equation for the relationship between relative prices and relative wages and to estimate a 'mandated wages' equation that indicates what change in relative wages is implied by the change in relative prices (e.g. Lawrence and Slaughter (1993); Baldwin and Cain (2000); Leamer (1998b); Harrigan and Balaban (1999); Lücke (1997)). This approach typically assumes two factors of production (skilled and unskilled labour) employed in a two-sector (skill-intensive and unskilled-intensive) economy. Goods are homogeneous and markets are perfectly competitive so that prices are set on World markets. Technology is common across countries. Factors are perfectly mobile within national borders, but fixed at a national level. In these circumstances, as long as the economy lies within its cone of diversification, then factor prices are simply a function of World traded prices. For example, in a two-factor CES model, output of sector $i$ is given by

$$
Y_{i}=A_{i}\left(\beta_{i} U_{i}^{\frac{\sigma-1}{\sigma}}+\left(1-\beta_{i}\right) S_{i}^{\frac{\sigma-1}{\sigma}}\right)^{\frac{1-\sigma}{\sigma}}
$$

Based on equation 1, we can derive a mandated labor demand equation. For illustrative purposes, we can choose a starting point where unskilled-intensive price, $P_{M}$ and the price of the skilled-intensive good $P_{X}$ are both normalized at 1 , and then derive the sensitivity of wages to changing just $P_{M}$ (we concentrate on advanced countries where unskilled-intensive goods are net imports)

$$
\frac{\partial \ln \frac{W_{s}}{W_{u}}}{\partial \ln P_{M}}=\frac{\beta_{X}{ }^{\sigma}}{\beta_{X}{ }^{\sigma}-\beta_{M}{ }^{\sigma}}-\frac{\left(1-\beta_{X}\right)^{\sigma}}{\left(1-\beta_{X}\right)^{\sigma}-\left(1-\beta_{M}\right)^{\sigma}} .
$$

Since $\beta_{M}>\beta_{X}, \frac{\partial \ln \frac{W_{s}}{W_{u}}}{\partial \ln P_{M}}$ is negative. If initial factor intensities are very close together $\left(\left(\beta_{M}-\beta_{X}\right) \longrightarrow 0\right.$ ), the elasticity will tend towards infinity. Also, as $\sigma$ tends to zero, $\frac{\partial \ln \frac{W_{s}}{W_{u}}}{\partial \ln P_{M}}$ tends to infinity.

The mandated wages equation can be estimated by time-series or panel methods. Since most published data on traded goods prices show relatively little movement over time, most studies conclude that trade (working through traded goods prices) can only have been responsible for small changes in relative wages. Hence, technological factors must have been responsible for most of the rise in inequality. Interestingly, Haskel and Slaughter (2001) and Haskel and Slaughter (2002) find similar results when they estimate mandated wages based on different rates of computerization by sector, rather than traded goods prices.

To understand the limitations of the single-equation approach, even though it is based upon general equilibrium theory, it is worth reviewing the reduced form, mandated-wages model in 1 and 2 . When the skilled/unskilled wage ratio, $\ln \phi$ is regressed upon $\ln P_{M}$, we derive a coefficient for the mandated wages model which can then be used in attributing some of the change in wages to World traded prices. The first problem is that share parameters $\beta_{X}$ and $\beta_{M}$ are very likely changing over time, so that regression techniques may find it difficult to distinguish between the effects of a steady change in terms of trade or biased technical progress. 
Hence there is an identification problem. ${ }^{8}$ In addition, there is probably a specification problem because the assumed Heckscher-Ohlin formulation does not accurately reflect a real-life open economy with nontradable goods, two-way trade within industries, and different goods prices depending on the source country. Prices are typically much lower for a given good imported from a poorer country. This observation implies that goods are differentiated. And while there is little evidence of import prices from a particular country changing greatly over time relative to other source countries (Neven and Wyplosz, 1996), the share of cheap unskilledintensive goods from poorer countries in total imports has risen sharply over the years. Hence, it would be misleading to state that the prices of unskilled-intensive imports have effectively been constant.

Ironically, once we allow for product differentiation with respect to source countries, a second problem emerges: these models are difficult to reconcile simultaneously with price/wage and output data. In Figure 2 below, we compare the effect of a global price shock in a small, open economy, based on alternative factor substitution elasticity assumptions.

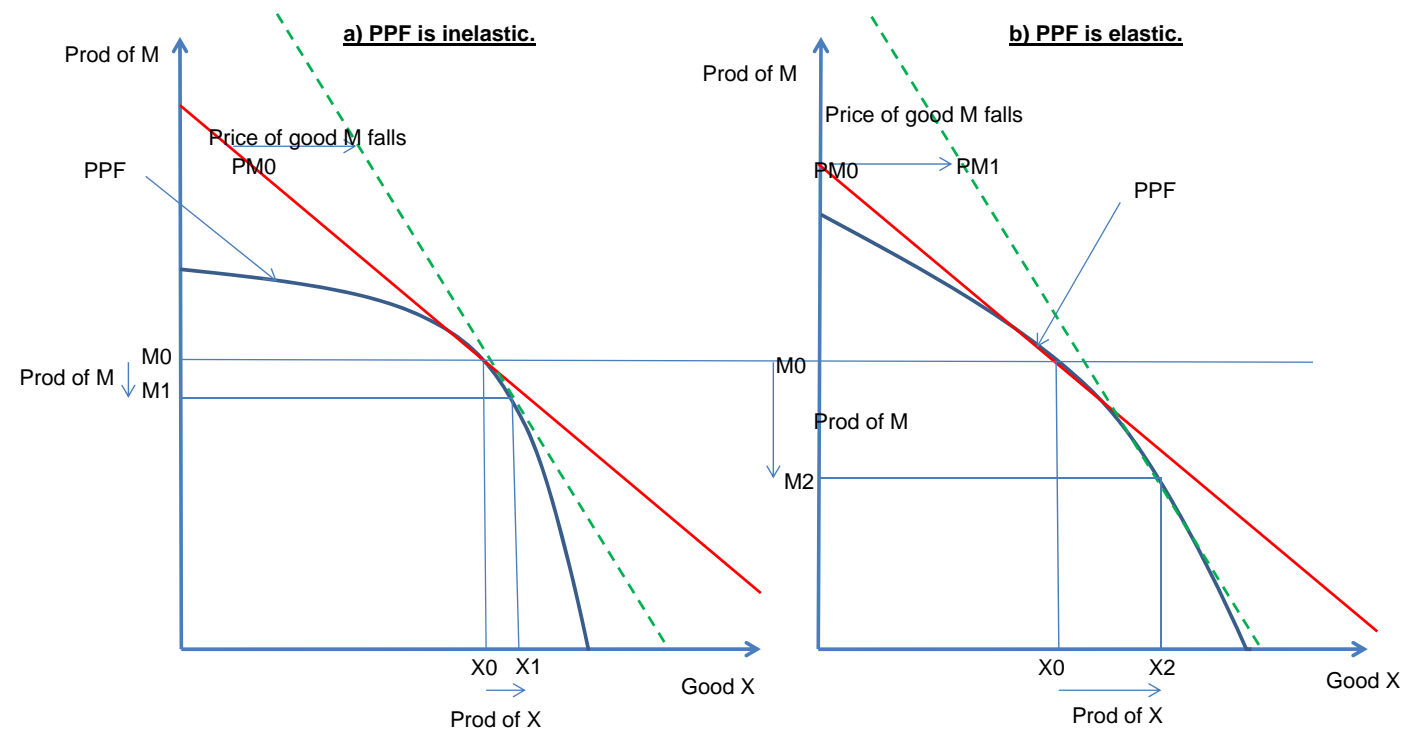

Figure 2: Effects of a price change on output in a small, open economy

Panels a and $\mathrm{b}$ in Figure 2 show a 2 good economy ( $\mathrm{M}$ and $\mathrm{X}$ ), subject to the same price shock (a fall in the

\footnotetext{
${ }^{8}$ We acknowledge here that it is possible to make some adjustments to improve upon the mandated wages equation in 2 , for example by including measures of sectoral TFP and factor income shares, which deals with at least some omitted variable bias.
} 
price of $\mathrm{M}$ ), but with a lower elasticity of substitution between factors of production $\sigma$ in panel a. In this case, following equation 2, the response of wages to a price shock is sizable; nevertheless, as there is little change in factor intensities, it is difficult to reallocate factors of production across sectors and alter the output mix of the economy.

By contrast, panel $\mathrm{b}$ shows an equivalent shock in a highly flexible economy (i.e. a high elasticity of substitution $\sigma$ ). Since factor intensities can now change easily in response to a change in wages, we see a large shift in the output mix while Equation 2 indicates that relative wages may not change greatly.

It is quite possible that a mandated wages regression will indeed show a small relative change in wages in response to the observed change in traded prices. The temptation from a single equation study would be to show that the elasticity of substitution is low.

By only examining the wage/price relationship, single equation studies usually miss this important crosscheck: whether the implied wage changes from other variables are actually consistent with both the model and the observed start and end year input and output quantities, as well as wages and prices.

The PPF in panel a is broadly consistent with the relatively modest changes in the structure of output seen in most advanced economies. However, in this case, the implied value of $\sigma$ is low, so relative wages should be rather responsive to prices - more so than single-equation estimated models usually indicate. This apparent contradiction could, in theory, be resolved if some other factor were also changing: for example, if the decline in unskilled-intensive goods prices were offset by faster technical progress in that sector. Unfortunately, studies such as Haskel and Slaughter (2002) indicate that technical progress in unskilled-intensive sectors was relatively slow. Hence the model again does not seem to fit the data.

Hence, the supposed theoretical advantages of the single-equation, mandated wages models are arguably illusory because they usually focus on only one causal factor (price or technology), whereas several contributory factors must be changing simultaneously to explain the observed changes in wages and output. Two important modifications are needed for a general-equilibrium based analysis to be plausible: first, we must abandon the assumption that domestic and imported goods are homogeneous (Abrego and Whalley, 2003); and second, we must not assume perfect factor mobility across sectors (Edwards and Whalley, 2007). Both assumptions dilute the impact of a price shock: in the first case, because a fall in the traded price of a good need not be fully reflected in domestic prices; in the second case, Jones (1965)'s factor price magnification effect is dampened by factor specificity (Neary, 1978). Both modifications require more explicit, structural models.

As an alternative to single-equation reduced-form estimation techniques such as mandated wage regressions, computable general equilibrium (CGE) techniques set out a more disaggregated, multi-equation model, usually calibrated rather than estimated. The use of calibrated models is discussed in detail in Dawkins et al. (2001). Calibration is a limited technique in that it is reliant upon the use of 'plausible' parameter estimates pooled from elsewhere in the literature. Such simulations are rarely testable statistically, but their qualitative properties and stability are testable by sensitivity analysis. On the other hand, calibrated models can be larger than economet- 
rically estimated models, can ensure consistency, and may be restricted to ensure plausibility across a variety of properties (in contrast to single-equation mandated wages equations which may fit well with observed wage changes, but often have implausible implications for output and employment changes). This said, even a CGE model may at times behave implausibly - but such problems often become apparent during the processes of calibration and simulation. The calibration technique also allows for the use of estimated parameters from a variety of studies (macro- or microeconometric and others). However, since a CGE model has to be calibrated to data on employment, prices, trade, wages, output and incomes, for several sectors and factors of production, the data requirements are large. Simplifications and data adjustments may need to be made when we compile the underlying Social Accounting Matrix (SAM) in order to ensure consistency with the assumed model structure.

Double-calibrated models for decomposition analysis differ from most previous CGE analysis in the sense that most CGE studies are calibrated to data (specifically, the social accounting matrix) for a single year. The normal procedure is to make sufficient restrictions to the model (in the form of key parameter assumptions, such as elasticities) to ensure that there is the same number of unidentified parameters as data points in the model, which in turn equal the number of independent equations to be solved. We then have an invertible matrix which yields exact calibration of the parameters for that year. Such parameters include technological efficiency and share parameters for each sector in the database.

It is not difficult to extend this procedure to cover both a start and an end year. In this case, social accounting matrices are constructed for both years, using consistent data definitions. The same model can be calibrated separately to data for each year, yielding two sets of parameters. This will yield exact identification of scale and share parameters in production and consumption for all sectors, as before, subject to the assumed model structure and elasticity assumptions being 'correct'. Alternatively, one might trade off restrictions across the two years for fewer assumptions about elasticity or other parameters within each year: for example, one could hypothetically fix the share parameters in one industry while endogenizing the elasticity of substitution. Either approach is possible.

Decomposition then consists of running counterfactual simulations of the model, gradually changing calibrated technological and other parameters one by one from their starting to their end values. When we have changed all parameters from their starting to their final values, the CGE model replicates the final year dataset (to which it was calibrated). Thus, we have a useful tool for simultaneously decomposing the changes in all the variables in the microconsistent dataset. This includes distribution, sectoral composition of output, trade volumes, GDP growth, employment and many more variables. Hence we have an integrated decomposition model covering a wide variety of economic variables. Critically, double calibration ensures that the combinations of share and scale parameter changes in a double-calibrated model are consistent with the price and output data simultaneously. 


\section{The Model}

Having established the principles of a double-calibrated CGE model, we now extend these to a more general, multi-sectoral model that is focused on separating out the effects of technological progress, capital cheapening, and increasing unskilled-intensive imports on wage inequality. Our SAM incorporates intermediate inputs, reflecting the emphasis in the literature on the role they play (Feenstra and Hanson, 1996). In addition, due to the potential 'over-flexibility' of the Heckscher-Ohlin model (see above), we modify this approach and use use relatively 'conservative' assumptions on trade structure - for example, the Armington assumption of imperfect substitution between imports from different countries of origin (following Abrego and Whalley (2003)) and imperfect intersectoral mobility of labour (Edwards and Whalley, 2007). These seem more consistent with observed data (Edwards and Whalley, 2007), avoiding the extreme sensitivity of the trade price/ factor price magnification effect observed in other models.

The equations of our schematic general equilibrium model are set out in the Appendix. Although larger than previous double-calibrated models, our model is still relatively small and based around an Armington trade structure, with nested production and consumption functions. The scale of the model has been chosen so we can use the looped simulation procedure described below.

\subsection{Key features}

Our economy employs four factors: skilled and unskilled labour $(S$ and $U)$, capital $(K)$, and land $(D)$. Factors are not internationally mobile. $S$ and $K$ are assumed to be fully mobile between sectors (given the gap of 21 years over which the calibration is being carried out). However, $U$ is only partially mobile between sectors, as in Edwards and Whalley (2007) and based upon Greenaway et al. (2000). Land (D) is only employed in one sector and permanently fixed.

The production side of the model is shown in Figure 3. The economy has four production sectors: $E$ is the exportable goods sector and relatively skill-intensive; $M$ is the import-competing sector and unskilledintensive; $N$ is the (relatively) nontradable part of the services sector and relatively skilled-intensive in the UK; and $F$ covers farming and fuels which employs relatively little labour, but has seen its relative price fall sharply over the period.

Like the econometric study by Krusell et al. (2000), we investigate the effects of assuming that skilled labour and capital are complements (an assumption justified by many econometric studies, starting with Griliches (1969)), but substitutes for the other factors (unskilled labour and land). We achieve this by employing a nested CES production function structure, with the lower level of the nest (elasticity of substitution $\leq 1$ ) aggregating capital and skill, and the higher level (elasticity of substitution $\geq 1$ ) combining the aggregate with the other factors. We investigate a range of parameterizations on the substitution elasticities between skilled labour, capital, and unskilled labour. 


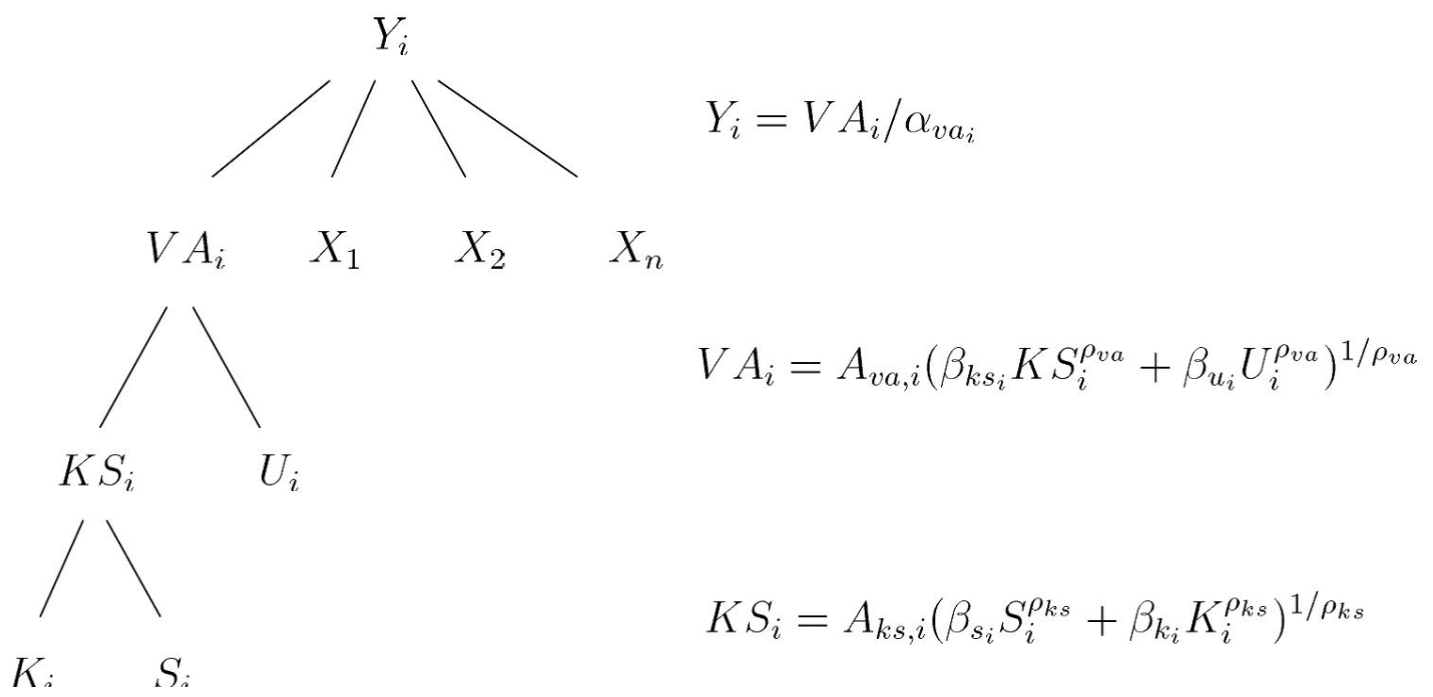

Figure 3: The nested production structure.

At the top level of nesting in Figure 3, value added, $V A_{i}$ and intermediate, $X_{j, i}$ inputs are constant proportions of gross output $Y_{i}$. One level down, value added is a CES combination of a capital-skill aggregate, $K S_{i}$ and unskilled labour, $L U_{i}$ :

$$
V A_{i}=\alpha \overline{t o p} p_{i} \cdot\left(\beta \bar{k} s_{i} \cdot K S_{i}^{\rho \overline{t o p}}+\bar{\beta} u_{i} \cdot L U_{i}^{\rho \overline{t o p}}\right)^{\frac{1}{\rho t o p}}
$$

All parameters and variables are defined in the Appendix, where there is also a full equation listing. The first-order conditions for cost-minimization imply that unskilled labour demand per unit value added in sector $i$ will satisfy the following function of the wage relative to value added price:

$$
\frac{L U_{i}}{V A_{i}}=\frac{P V_{i}}{W u_{i}}{ }^{\frac{1}{1-\rho t o p}} \alpha t \overline{p p}_{n, i} \cdot\left(\frac{\beta \bar{u}_{n, i}}{\beta \bar{u}_{n, i}}\right)^{\frac{1}{1-\rho t o p}} .
$$

The demand for the capital-skill aggregate is of similar form.

In turn, the capital stock and skilled labour are functions of total demand for the KS aggregate and the relative skilled wage relative (or capital price) relative to the price of the capital-skill aggregate. Hence, skilled labour input into each industry will satisfy

$$
\frac{L S_{i}}{K S_{i}}=\frac{P K S_{i}}{W s_{i}}{ }^{\frac{1}{1-\rho k s}} \alpha \bar{k} s_{i} \cdot \beta \bar{s}_{n, i}^{-\frac{1}{1-\rho k s}}
$$

The equation for capital input is similar (see Appendix).

On the consumption side, we assume simply that the representative consumer spends her income across the goods classes to maximize utility subject to a Cobb-Douglas consumption function. Hence, if the consumer's 
utility is

$$
U=P i_{i} C_{i}^{\gamma \operatorname{con}_{i}}
$$

then maximising utility subject to spending $C O N$ on consumption, and facing (Armington) aggregate prices of $P A_{i}$ for each good means that consumers will spend

$$
C_{i}=\frac{C V_{i}}{P A_{i}}
$$

Capital stock is chosen by firms to maximize profits, subject to an assumed interest and depreciation cost. Capital goods investment is assumed to be consistent with replacement of depreciation and a constant growth rate of the capital stock(derived from calibration). Hence, investment volume

$$
I_{n}=\sum_{i}\left(G K_{n}+\bar{\delta}\right) \cdot K_{n, i} .
$$

Capital goods are produced from a mixture of inputs, again with fixed shares.

Trade conforms to the Armington (1969) assumption where domestic goods are combined with imports from a variety of sources in a CES aggregation. Hence, after solving the first order conditions, the use of good i from each country c corresponds to:

$$
M V O L_{n, c, i}=T U_{n, i} \cdot P A_{n, i}^{\frac{1}{1-\rho a \bar{e} m}} \cdot \alpha \bar{u} s e_{n, i}^{\frac{\rho a \bar{e} m}{1-\rho \operatorname{ae} m}} \cdot\left(\frac{\beta \bar{u} s e_{n, c, i}}{P F_{n, c, i}}\right)^{\frac{1}{1-\rho a \bar{e} m}} .
$$

Elasticities are drawn from the literature and subject to sensitivity analysis.

The final set of equations needed to solve the economy are those solving for goods market balance, balance of incomes and expenditure and clearance of the skilled and unskilled labour markets. Note that we assume that the balance of trade remains constant.

\subsection{The microconsistent database}

Input-output data were derived for 1979 and 2000 from the published OECD tables; Social Accounting Matrices for both years are shown in the Appendix.

Sectors with a stronger relative employment of manual workers are classified as unskilled-intensive. Data for these calculations stems from the monthly publication Labour Market Trends by UK statistics (2003). 14 out of 48 sectors have been identified as non-tradable because their import-export to output ratios are less than or equal to 11 per cent in 2000. While this threshold is arbitrary, others have used similar cut-off points (Pavcnik (2002) uses 15\%). Due to price volatility, we aggregate primary sectors (i.e. agriculture, mining and quarrying of energy-generating resources, and electricity, gas, and water supply) into a separate sector.

For wage calculations, we take into account possible differences in the hours worked by the two groups of 
workers, $U$ and $S .^{9}$

Price indices for each sector are calculated from the OECD STAN database, using a chain Laspeyres weighting. Setting 1982=100, our calculated indices for 2000 are: $M=97.9, E=91.0, N=117.6, F=60.4$. Note that we cannot obtain good-quality price series for years prior to 1982 , due to changes in published data series.

\subsection{The double calibration}

Traditional general equilibrium models are calibrated on a single year by fitting a series of (share and scale) parameters to the set of price and volume data, once elasticities have been decided upon. By contrast, we follow Abrego and Whalley (2003), Edwards and Whalley (2007), Okushima and Tamura (2009), and others and calibrate the model on both, the start and the end year. Essentially, if we can calibrate the relevant parameters for one year, based upon our assumed elasticities and the available social accounting matrix and price data, then we can also perform a similar, unique calibration for a second year. Then we can derive the only combination of sector-biased (total factor productivity growth) and factor-biased technological change in each sector that is consistent with the observed SAMs and assumed elasticities.

\subsection{Share and scale parameters.}

In calibrating the production function, we pay particular attention to distinguishing between and decomposing accurately the factor and sector biasses of technolcogical change. We define these as follows.

Pure factor bias is a change in parameters such that, for a given set of factor input prices, the relative inputs of some factors increase while others decrease, in such away that the overall unit production cost of output is unchanged.

Pure sector bias is a change in parameters which changes the relative production costs of different sectors without altering the ratio of inputs (at given input prices) within each sector.

These definitions raise some important issues in the case of a CES production function. As an illustration, the CES zero profit condition yields a price

$$
P_{i}=\left(\frac{1}{A_{i}}\right)\left[\beta_{u, i}^{\frac{1}{1-\rho}} w_{u, i}^{\frac{\rho}{\rho-1}}+\left(1-\beta_{u, i}\right)^{\frac{1}{1-\rho}} w_{s, i}^{\frac{\rho}{\rho-1}}\right]^{\frac{\rho-1}{\rho}} .
$$

The ratio of factor inputs is given by

$$
\frac{U_{i}}{S_{i}}=\left(\frac{\beta_{u, i}}{1-\beta_{u, i}}\right)^{\frac{1}{1-\rho}}\left[\frac{w_{s, i}}{w_{u, i}}\right]^{\frac{1}{1-\rho}}
$$

which reflects the constant elasticity of substitution property. Straightaway, from inspecting equations 10 and

\footnotetext{
${ }^{9}$ While we use non-manual and manual as proxies for skilled and unskilled labour, respectively, we are aware that this classification does not necessarily reflect workers' actual skills. For example, most workers in the service sectors are non-manual, but many are not highly skilled (think of cleaning personnel). The principal problem here is data availability for the early years.
} 
11, we can see that a change in $A_{i}$ affects sectoral prices, but does not affect the ratio of inputs: hence a change in $A_{i}$ represents technological progress that is Hicks-neutral and has a sector bias, but no factor bias.

By contrast, from inspecting equation 11, a change in $\beta_{u, i}$ clearly represents factor-biased technological change. However, differentiating equation 11 with respect to $\beta_{u, i}$, it can be shown ${ }^{10}$ that $\frac{\partial P_{i}}{\partial \beta_{u, i}}=0$ if and only if $U_{i}=S_{i}$. Otherwise, the change in $\beta_{u, i}$ will have both sector- and factor-biased effects. If the rise in $\beta_{u, i}$ increases the input (per unit of output) of the more intensively-used factor, then it will increase the output cost of that sector, and so should be considered to have a sector-biased effect as well. ${ }^{11}$

Over a 21 year period, share parameters shift quite significantly, and if the above correction is not made, the breakdown of 'factor bias' and 'sector bias' effects is potentially misleading. ${ }^{12}$

\subsection{Possible causes of growing inequality in our database}

We now examine how the possible causes of growing inequality discussed in Section 2 show up in the database and are handled in our decompositions.

1. Trade. While we would ideally like to model trade in terms of international trade prices (along the lines of Edwards and Whalley (2007), using data from Neven and Wyplosz (1996)), in practice it is difficult to obtain reliable price data and adjust for differences in quality, changing trade costs, and potential product variety across countries. Therefore, we use the Armington approach to modelling trade so that changes in price, quality, variety and search costs for trade partners are effectively incorporated as shifts in the trade share parameters. Changes in net exports by sector are shown below:

Table 2: Net exports/GDP

\begin{tabular}{llllll}
\hline & Year & $\mathbf{M}$ & $\mathbf{E}$ & $\mathbf{N}$ & $\mathbf{F}$ \\
per cent & $\mathbf{1 9 7 9}$ & -1.47 & 1.68 & 1.36 & -2.04 \\
& $\mathbf{2 0 0 0}$ & -1.87 & 0.50 & -0.01 & 0.25 \\
\hline
\end{tabular}

Data aggregated from the OECD input-output tables into the format of our SAMs for 1979 and 2000. Please note that 'nontradables' have been defined as sectors with a low trade/output ratio, so in fact total trade is not entirely zero.

Note that it is difficult to reconcile these observed trade patterns with a Heckscher-Ohlin trade model, since such a model tends very rapidly towards complete specialization, unless the supply side of the economy is very inelastic. In an Armington setup the sensitivity of local incomes to World traded prices is more damped. Nevertheless, a number of studies (following Anderson and van Wincoop (2004)) have derived relatively high Armington substitution elasticities, at least in the longer term, and so we consider a wide range of elasticities, from 2.5 up to 20. [Fouquin and Hugot (2016) suggests an elasticity of 5.02, but other studies suggest it is somewhat higher, notably those based upon Eaton and Kortum (2001)].

\footnotetext{
${ }^{10}$ Proof available from the authors on request.

${ }^{11}$ This point has been missed by much of the previous literature such as Abrego and Whalley (2003) or Chusseau et al. (2008).

${ }^{12}$ Details available on request.
} 
Table 3: Imports and exports as percent of UK demand

\begin{tabular}{lllllll}
\hline Sector & Imports & & \multicolumn{5}{c}{ Exports } \\
& $\mathbf{1 9 7 9}$ & $\mathbf{2 0 0 0}$ & change & $\mathbf{1 9 7 9}$ & $\mathbf{2 0 0 0}$ & change \\
$\mathbf{M}$ & 21.1 & 32.3 & 11.2 & 19.2 & 19.5 & 0.3 \\
$\mathbf{E}$ & 11.3 & 15.0 & 3.6 & 14.6 & 18.4 & 3.8 \\
$\mathbf{N}$ & 6.0 & 4.7 & -1.3 & 7.9 & 1.6 & -6.3 \\
$\mathbf{F}$ & 32.2 & 16.6 & -15.6 & 19.7 & 19.2 & -0.5 \\
\hline
\end{tabular}

Data aggregated from the OECD input-output tables into the format of our SAMs for 1979 and 2000.

In table 3, we compare imports and exports for each sector with total UK demand. The most notable change is the rise in the share of imports in unskilled-intensive sector $\mathrm{M}$, although there is also a smaller rise in sector E (where exports rise by a similar amount). This emphasises that the Armington model can potentially (if the elasticity of substitution is not too high) give quite a substantially different trade effect to a HOS model: in the HOS case, the slight rise in relative traded prices of the importable sector would indicate that trade is not a factor in increasing inequality (as Lawrence and Slaughter (1993) and others have argued, whereas in the Armington case, there is a downward shift in the domestic share coefficient for good $\mathrm{M}$ in the Armington case, which consists of an inward movement in the demand curve for UK produce in the unskilled-intensive sector. One other point to mention on trade: the UK moved from a trade surplus in 1979 to a deficit in 2000, which may have benefited real wages.

2a. Factor-biased technical progress. The scale and share parameters are calibrated to ensure the production functions 'fit' after all the other causal factors (such as changes in demand and prices) have been taken into account. It should be noted that technology is still being treated as a residual in this calibration. The main advantages over residuals derived from reduced form econometric estimation are i) that we are able to consider more complicated (and realistic) functional formulations and ii) we are testing the consistency of the entire model against data, not just the few variables which appear in a reduced form equation.

Table 4: Factor shares in per cent: low elasticity case

\begin{tabular}{llllll}
\hline & & $\mathbf{M}$ & $\mathbf{E}$ & $\mathbf{N}$ & $\mathbf{F}$ \\
$\frac{\beta_{s}}{\beta_{k g}}$ & 1979 & 1.87 & 2.15 & 3.04 & 0.21 \\
& 2000 & 1.80 & 1.48 & 1.08 & 0.07 \\
& Does shift favour skilled? & $\mathrm{N}$ & $\mathrm{N}$ & $\mathrm{N}$ & $\mathrm{N}$ \\
\hline$\frac{\beta_{k s}}{\beta_{u}}$ & 1979 & 66.35 & 68.35 & 217.55 & 138.11 \\
& 2000 & 117.79 & 248.43 & 415.76 & 394.10 \\
& Does shift favour skilled? & $\mathrm{Y}$ & $\mathrm{Y}$ & $\mathrm{Y}$ & $\mathrm{Y}$ \\
\hline
\end{tabular}

Data aggregated UK Labour Force Surveys.

The following table shows the shifts in calibrated share parameters at the lower level $\left(\beta_{s} / \beta_{k g}\right)$ and the higher 
level $\left(\beta_{k s} / \beta_{u}\right)$ in our low elasticity case. In all sectors, there has been a shift in share parameters towards using more of the capital/skill aggregate $(k s)$ rather than unskilled labour, but that, within that aggregate, there has been a shift towards using more capital relative to skilled labour, so the net effect on skilled/unskilled demand is not immediately apparent.

Table 5: Changes in calibrated share parameters

\begin{tabular}{llllll}
\hline \multirow{4}{*}{ Lower level } & $\mathbf{1 9 7 9}$ & $\mathbf{M}$ & $\mathbf{E}$ & $\mathbf{N}$ & $\mathbf{F}$ \\
& $\mathbf{2 0 0 0}$ & 0.49 & 0.58 & 0.69 & 0.25 \\
& Change & -0.05 & -0.14 & -0.32 & -0.12 \\
Higher level & $\mathbf{1 9 7 9}$ & 4.94 & 2.93 & 2.90 & 4.55 \\
& $\mathbf{2 0 0 0}$ & 4.34 & 2.94 & 2.20 & 3.33 \\
& Change & -0.60 & -0.02 & -0.70 & -1.22 \\
\hline
\end{tabular}

Calibration of our SAMs, fitting the model equations.

2b. Sector-biased technical progress. The shift in consumer spending towards nontradable goods, and the rising share of imports among import-competing sectors both favour skilled rather than unskilled labour. So does the cheapening of capital, since skill-intensive sectors also tend to be more capital-intensive.

It is worth noting that sector bias derives primarily from a shift in the relative industry scale parameters. This will therefore interact with other factors, particularly the fall in capital prices. A fall in capital prices leads to a greater reduction in production costs, the more is the share of capital in the industry's output, and the lower the substitution elasticity with other factors. Hence, in cases where the substitution elasticity out of capital is low, capital cheapening on its own will lower the relative price of goods from the capital-intensive exportable sector. Since we are calibrating to actual changes in goods prices, which do not change greatly over time, it follows that, in this case, there needs to be an offsetting sector-biased technical progress in favour of the other sectors.

Concentrating on the higher-level scale parameter, there seems to have been considerable TFP growth in fuels, nontradables and (perhaps surprisingly) import-competing sectors, but none in the exportable sector. The progress in the importable sector may reflect firm-selection ('batting order') effects: as the sector has declined, inefficient firms or plants have been weeded out and remaining capacity restructured quite radically, raising overall TFP. Importables, fuels nontradable sectors may all have gained in productivity from the removal of subsidies during the 1980s. By contrast, the growth in labour productivity in our exportable sector seems to be explained in terms of rising capital inputs, rather than TFP.

3. Capital cheapening, combined with capital-skill complementarity. As a rough proxy for capital cheapening, and following Bakhshi and Thompson (2002) and Baumann and Price (2007), we have assumed a 50\% fall 
Table 6: Changes in calibrated scale parameters

\begin{tabular}{llllll}
\hline & & $\mathbf{M}$ & $\mathbf{E}$ & $\mathbf{N}$ & $\mathbf{F}$ \\
Lower level & $\mathbf{1 9 7 9}$ & 0.54 & 0.58 & 0.69 & 0.25 \\
& $\mathbf{2 0 0 0}$ & 0.49 & 0.44 & 0.37 & 0.12 \\
& Change & -0.05 & -0.14 & -0.32 & -0.12 \\
Higher level & $\mathbf{1 9 7 9}$ & 4.94 & 2.93 & 2.90 & 4.55 \\
& $\mathbf{2 0 0 0}$ & 4.34 & 2.94 & 2.20 & 3.33 \\
& Change & -0.60 & -0.02 & -0.70 & -1.22 \\
\hline
\end{tabular}

Calibration from our SAMs, fitting the model equations.

in the real cost of capital goods to industry over the period concerned, consisting of a $30 \%$ fall in the cost of producing investment goods and a roughly similar drop in the financial cost of capital.

4. Changes in consumer preferences. We have modelled consumer preferences with a Cobb-Douglas utility function, so that changes in expenditure shares over time will be reflected in changes in share parameters. Over time, nontradables (which in the UK are relatively skill-intensive) have been increasing, while importcompeting goods have declined. This has generally been ignored in the wage inequality debate: but Hillberry et al. (2005) show that changing consumer preference parameters are important in 'fitting' general equilibrium models of trade.

Table 7: Consumer expenditure shares

\begin{tabular}{llllll}
\hline & Year & $\mathbf{M}$ & $\mathbf{E}$ & $\mathbf{N}$ & $\mathbf{F}$ \\
per cent & $\mathbf{1 9 7 9}$ & 28.32 & 22.84 & 48.23 & 0.62 \\
& $\mathbf{2 0 0 0}$ & 19.18 & 21.51 & 57.11 & 1.59 \\
\hline
\end{tabular}

Data aggregated from the OECD input-output tables into the format of our SAMs for 1979 and 2000.

5. Labour supply changes. Using our blue-collar/white-collar definitions, the unskilled labour force in the UK declined by 23.5 per cent between 1979 and 2000, while the skilled labour force rose by 41.2 per cent. This reflects, in part, an improvement in overall educational levels. However, the change may not be entirely exogenous, since workers may retrain or spend longer in education in response to changing job opportunities. In addition, our current dataset has a deficiency, in that it does not distinguish between unskilled and semi-skilled blue-collar workers, or between professional/managerial and other white-collar workers.

In the low and high elasticity cases, our calibrated labour demand elasticities in 2000 are between -1.46 and -2.16 for unskilled labour, and between -1.21 and -1.88 for skilled. Nevertheless, even with the high case elasticities, the observed fall in the unskilled labour force would have been expected to raise unskilled wages by about $13 \%$ between 1979 and 2000, while the observed rise in the skilled labour force would have lowered skilled wages by about $17 \%$. These relative changes far outweigh the changes actually observed. 


\section{Decomposition Results}

To describe the results of our decomposition exercises by small steps, we report the fitted integrals of the components of the change in the wage ratio between skilled and unskilled labour, on the assumption that all the causative factors had been steadily changing. We explore in detail how sensitive our results are to our assumptions about factor mobility across sectors and about the elasticities of subsitution between factors of production and between imported vs. domestic varieties of each good (Armington elasticities).

We begin with four contrasting sets of assumptions about factor substitution elasticities in production (Figures 4 to 6). For each set of substitution elasticities, we let the Armington elasticity vary from 2.5 to 20 and also make alternative assumptions about inter-sectoral factor mobility. It turns out that neither the Armington elasticity nor the degree of factor mobility have an important impact on the relative weight attributed to each contributory factor. However, the degree of substitutability (or complementarity) between factors of production matters a lot, raising the question of which is the most plausible assumption.

We note that there is a far larger literature on the relationship between capital and aggregate labour than that between capital and skilled or unskilled labour. Although a unit elasticity was fashionable at one time, more recent studies suggest that there is overall complementarity, e.g. (Smith, 2008). Against this, Karabarbounis and Neiman (2014) find that capital and labour (as aggregates) are substitutes globally, with an elasticity of perhaps 1.3. This was criticized by Lawrence (2015), who argued that, once SBTP is allowed for, capital and labour turn out to be complements. In a similar vein, Oberfield and Raval (2012) argue that they are complements, with an elasticity of 0.7 . Grossman et al. (2017) use the assumption of overall complementarity between capital and labour to explain the fall in labour's share of income since 1980.

There are fewer papers building on the Griliches (1969) hypothesis of capital-skill complementarity, which would imply a substitution elasticity of below unity between capital and skill but a higher one between capital and unskilled labour. Correa et al. (2017) find evidence of complementarity between capital and skill, but show that this is greater the higher the technological component of the capital. Karabarbounis and Neiman (2014) estimate a similar type of nested CES function to that which we use, but only cite the substitution elasticity between a capital-skill aggregate and unskilled labour (about 1.3) without citing the substitution elasticity at the lower level between capital and skill.

It is worth noting that some studies tend to follow the related hypothesis of capital substituting for unskilled labour (Autor et al. (2017), Edwards and Perroni (2014)). This is not easily distinguished from capital-skill complementarity in a general equilibrium context. Other studies, such as Goos and Manning (2007) have focused on the 'polarization' of the job market (i.e. the hollowing out of middling skill jobs), which stresses that there are several different types of skill and labour characteristics, some of which are more threatened by either technology or capital cheapening than others. This is, however, hard to handle when looking at a binary division of the workforce. Meanwhile, León-Ledesma et al. (2010) emphasize the identification difficulties in estimation 
when both capital-labour complementarity/substitution and biased technical progress are present, although they also emphasise the superiority of using both output and input data (something which our discussion above also supports).

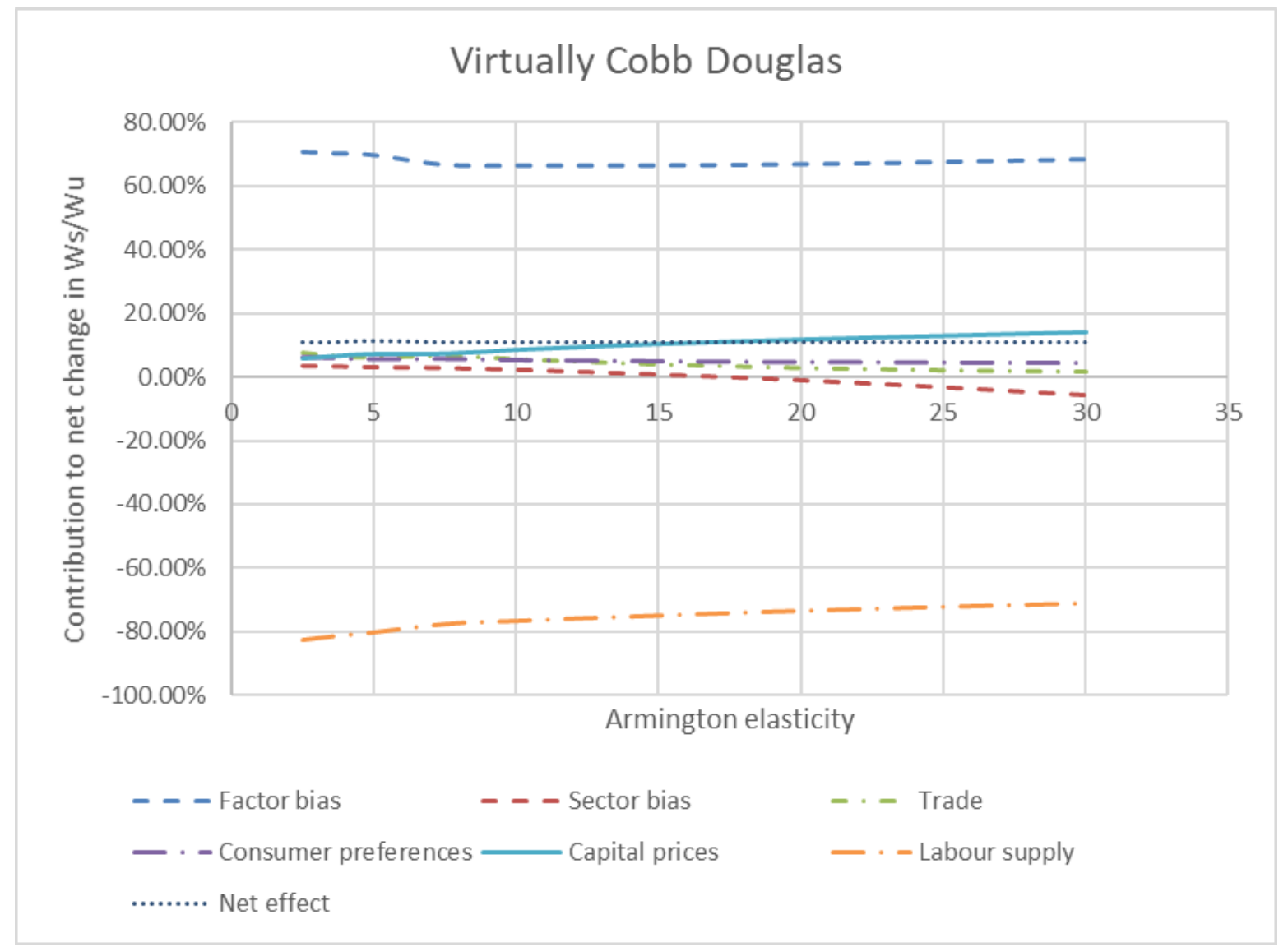

Figure 4: Decomposition related to Armington elasticity: virtually Cobb-Douglas production technology.

Given the uncertainties in the literature - albeit that there is perhaps more support than opposition to the idea that capital complements skilled labour and substitutes for unskilled labour - we adopt the strategy here of considering a range of plausible elasticities. We also note that there is relatively little evidence on these elasticities directly relating to the UK.

To establish a point of reference, we start with "virtually Cobb-Douglas" production functions where the lower-level elasticity of substitution between physical capital (K) and skilled labour (S) as well as the top-level elasticity of substitution between the composite of $\mathrm{K}$ and $\mathrm{S}$ and unskilled labour (U) are both very close to 1 (Figure 3). (Elasticities were as close to 1 as would consistently converge without reprogramming the model). 13 We assume slightly-less-than-perfect mobility of unskilled labour between sectors, with a final-year wage differential between $w_{u}$ in expanding and declining sectors of $2.5 \% .^{14}$

\footnotetext{
${ }^{13}$ The two elasticities are 1.025 and 0.975 , respectively. The specification of our model does not allow us to set them exactly to 1 .

${ }^{14} \mathrm{We}$ also run the full set of simulations for a final-year wage differential of $15 \%$, with essentially the same results.
} 
In Figure 4, the dotted line ("net effect") indicates the observed percentage increase in the skill premium, defined as the ratio of the skilled over the unskilled wage (plus 12 points from 1979 to 2000), as shown in Table $1 .{ }^{15}$ The remaining lines indicate the contributions of the various possible causal factors, depending on the assumed Armington elasticity (along the x-axis). If the world is indeed "Cobb-Douglas" as we assume here, only two factors stand out. First, the rising supply of skilled relative to unskilled labor, on its own, causes the skill premium to decline sharply (for example, by approximately $80 \%$ for an Armington elasticity of 5). Second, this negative effect is nearly offset by the effects of the factor bias of technical change in favor of skilled labour. All remaning factors have small positive effects on the skill premium, adding up to the observed increase of 12 percent.

In our second scenario (Figure 5), we assume modest capital-skill complementarity by reducing the lowerlevel elasticity of substitution between $\mathrm{K}$ and $\mathrm{S}$ to 0.667 while keeping the top-level elasticity between $\mathrm{S} / \mathrm{K}$ and $\mathrm{U}$ at 1.025. The rising supply of skilled labour and the factor bias of technical change affect the skill premium much as before. In addition, the declining prices of capital goods now exert a positive influence on the skill premium - roughly twice as large as the observed increase (net effect). With capital-skill complementarity, cheaper capital goods tend to replace unskilled labor, while at the same time they tend to increase demand for skilled labor. This positive effect of lower capital prices is partly offset by the sector bias of technical change. Total factor productivity has grown faster in unskilled-labour-intensive industries overall, implying a sector bias of technical change that sustains demand for unskilled labour and reduces the skill premium, ceteris paribus. This effect becomes larger for larger values of the Armington elasticity as a given relative productivity improvement allows more imports to be replaced by domestic production.

In our third scenario (Figure 6), we assume that capital and skilled labour are even more complementary, with a lower-level elasticity of substitution of 0.5 , while the top-level elasticity between $\mathrm{S} / \mathrm{K}$ and $\mathrm{U}$ remains at 1.025. The overall pattern of effects is unchanged, but the effects of declining capital prices (positive) and of the sector bias of technical progress in favor of unskilled-labour-intensive industries (negative) are both even more pronounced.

The three previous scenarios demonstrate that our assumptions about the complementarity or substitutability of factors of production affect in important ways what change in the skill premium we attribute to each of our six potential underlying factors as a result of our simulations. While the rising supply of skilled labour (negative) and the factor bias of technical progress in favour of skilled labour (positive) are important contributory factors in all scenarios, declining capital goods prices (positive) and the sector bias of technical progress in favour of unskilled-labour-intensive sectors (negative) matter most when capital and skilled labour are complementary and the composite of the two is highly substitutable with unskilled labour. By contrast, in all scenarios the contributions of international trade and consumer preferences to the change in the skill premium are small relative to all other contributing factors. Nevertheless, they sum to approximately the "net effect", i.e. the

\footnotetext{
${ }^{15}$ The increase was from a ratio of $1.48: 1$ to $1.6: 1$
} 


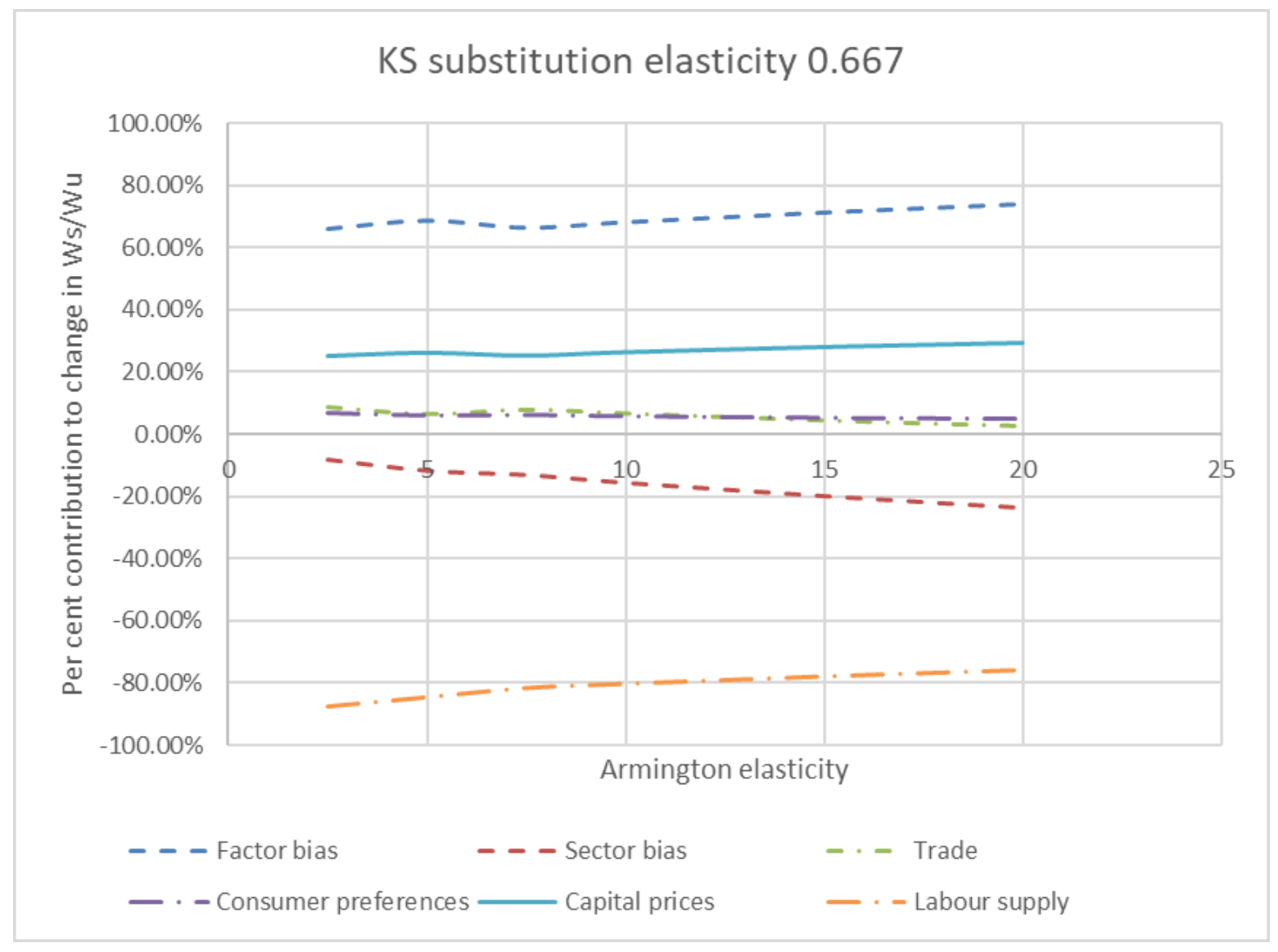

Figure 5: Capital and skilled labour complementary

observed change in the skill premium, and so should not be neglected.

We have also found that the Armington elasticity of substitution between imported and domestic goods has relatively little impact on our outcomes. Therefore, we now explore for a given value of the Armington elasticity (5.0: close to Fouquin and Hugot (2016)'s estimates) how our assumption of relatively high mobility of unskilled labour (an assumed wage difference of only $2.5 \%$ between expanding and contracting sectors at the end of the simulation period) affects our conclusions. We contrast our earlier findings with new simulations for much lower mobility of unskilled labour, represented by an assumed final-year wage difference of $15 \%$ (Figure 7). It turns out out that the degree of unskilled labour mobility has practically no effect on the results. We therefore proceed with our assumption of high inter-sectoral unskilled labour mobility.

Finally, we explore more systematically how the relative importance of the contributory factors to the rise in the skill premium changes as we move from a Cobb-Douglas world to one of prounounced capital-skill complementarity. We run scenarios over a grid of lower-level (K/S) substitution elasticities of 0.5, 0.6, 0.7, 0.8, 0.9 and 0.975 and higher-level $(\mathrm{KS} / \mathrm{U})$ substitution elasticities of $1.05,1.25$ and 1.5. We fix the Armington substitution elasticity at 5.0 and assume that unskilled labour is relative immobile between sectors (defined as 


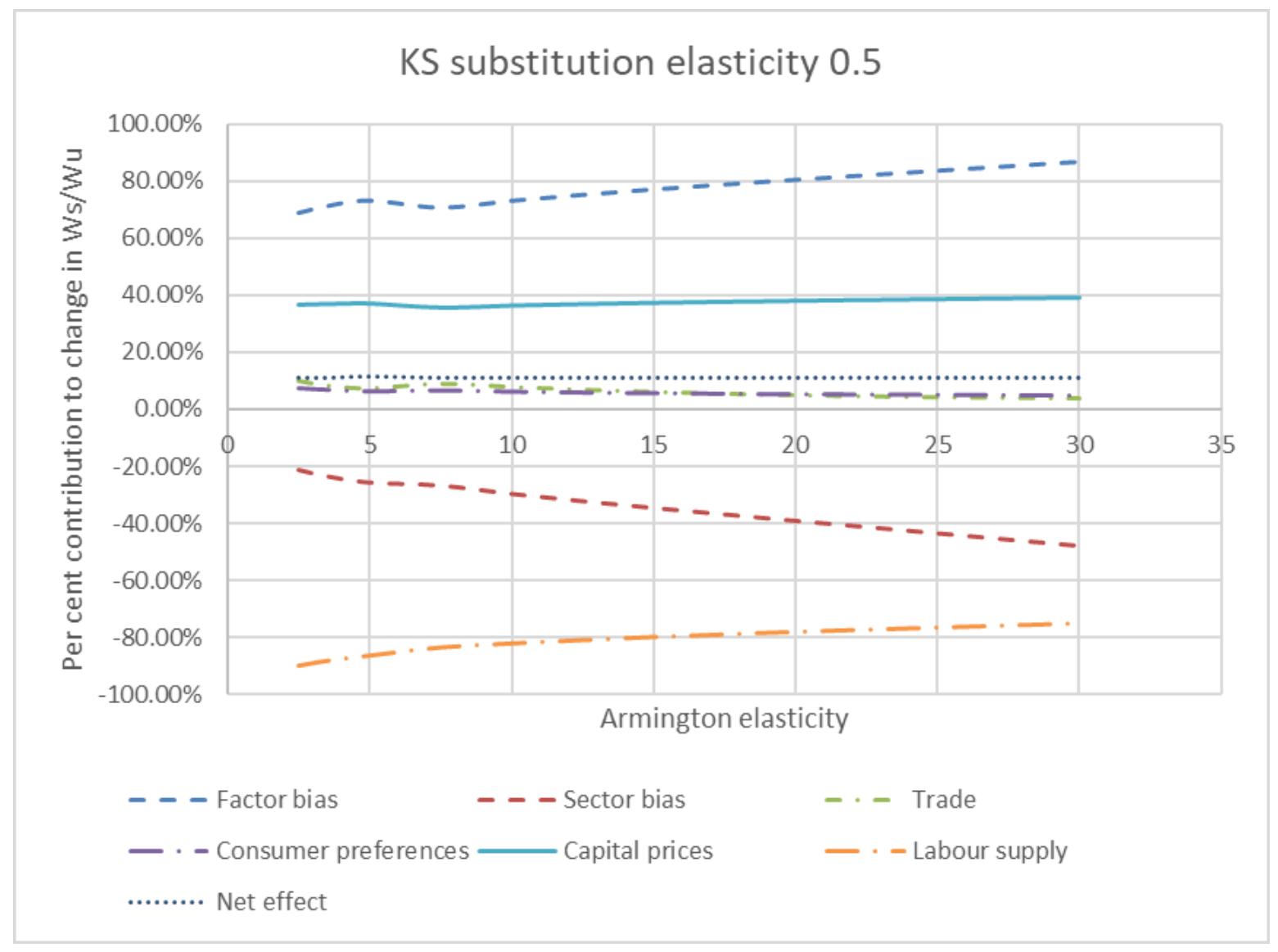

Figure 6: Capital and skilled labour strongly complementary

before by a $15 \%$ end-year wage differential between contracting and expanding sectors). We focus on the sector and factor biases of technical change and on declining capital prices because we have found (above) that the large negative effect on the skill premium due to the rising supply of skilled labour is not sensitive to factor substitution elasticities.

In the following three figures, the shaded areas indicate the approximate size of the effect on the skill premium, depending on the combination of factor substitution elasticities at the lower and top level. The upper left-hand corner represents our "almost" Cobb-Douglas world. As we move down, capital and skilled labour become complements; as we move right, the composite of $\mathrm{K}$ and $\mathrm{S}$ becomes more substitutable with unskilled labour.

The effect of declining capital prices on the skill premium (Figure 8), varies widely with the assumed factor substitution elasticities. In a Cobb-Douglas world (upper left-hand corner), declining capital prices do not matter because factor income shares are fixed. The effect on the skill premium that we attribute to rising capital prices increases when we assume that capital and skilled labour are more complementary (down) or the composite of $\mathrm{K}$ and $\mathrm{S}$ is more substitutable with unskilled labour (from left to right). 


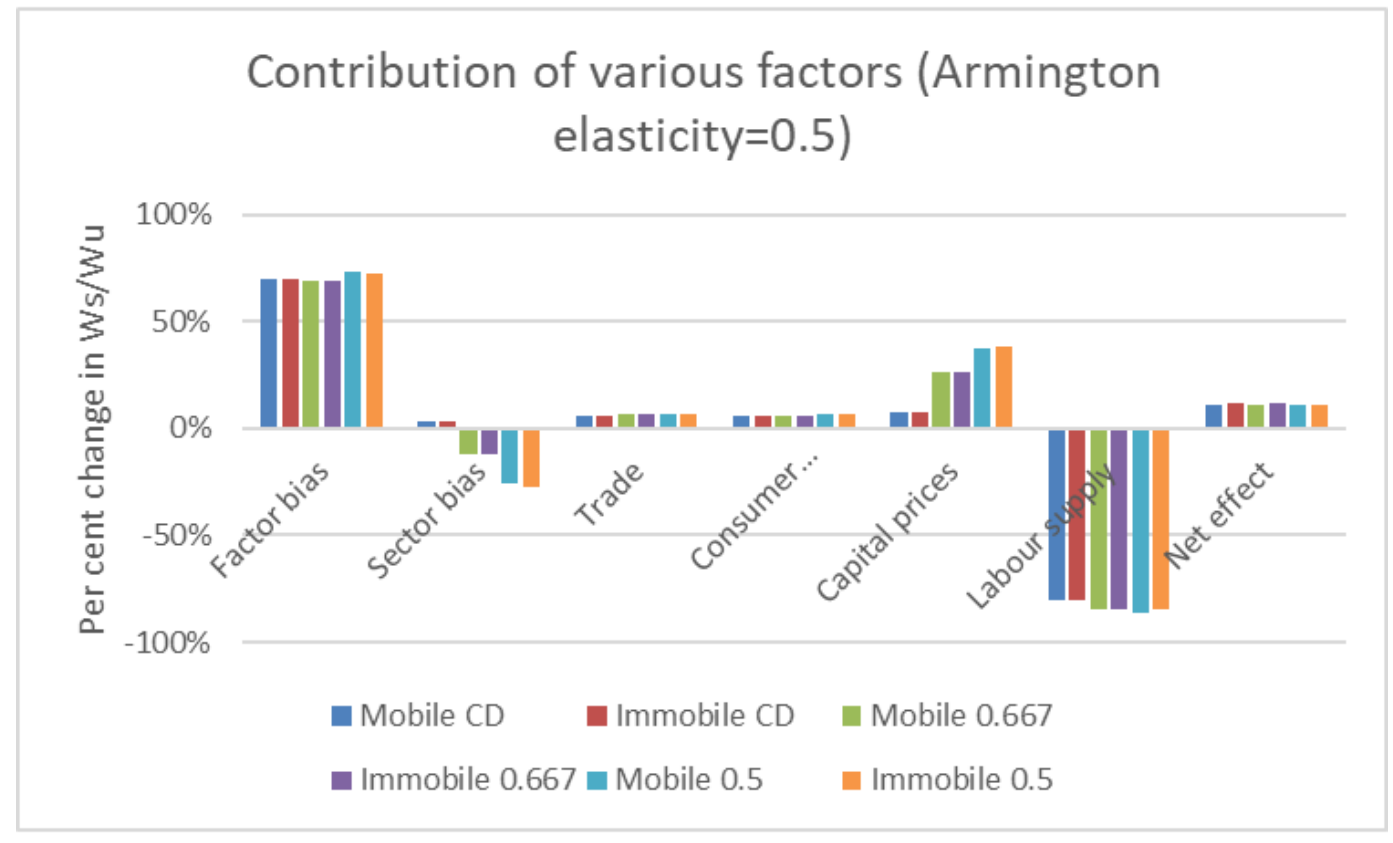

Figure 7: Breakdown of the contribution of various factors with an Armington elasticity of 5

These observations demonstrate the general point that any conclusion regarding the contribution of declining capital prices to growing inequality in the real world depends crucially on one's underlying assumptions regarding the shape of sectoral production functions. If one accepts in line with Krusell et al. (2000) that the notion of capital skill complementarity describes real-world sectoral production functions adequately, then one must conclude that declining capital prices are a major contributing factor to rising inequality.

The impact of the sector bias of technical change on the skill premium follows a somewhat similar pattern (Figure 9).

If we assume a Cobb-Douglas world, the impact of sector bias is small. It is also not much affected by the top-level elasticity of substitution between the composite of $\mathrm{K}$ and $\mathrm{S}$ and unskilled labour (left to right in Figure 9). However the negative effect of sector bias become large when capital and skilled labour are more complementary (going from top to bottom in Figure 9), offsetting in large part the corresponding positive effect of declining capital prices.

The factor bias of technical change (Figure 10) consistently contributes at least 40 percentage points to the rise in the skill premium - except when factors of production are highly substitutable at both the lower and top levels (i.e. in the upper right-hand corner in Figure 10. As we have shown in our first set of simulations (Figures 12 to 5), the factor bias compensates in large part for the negative effect on the skill premium of the rising 


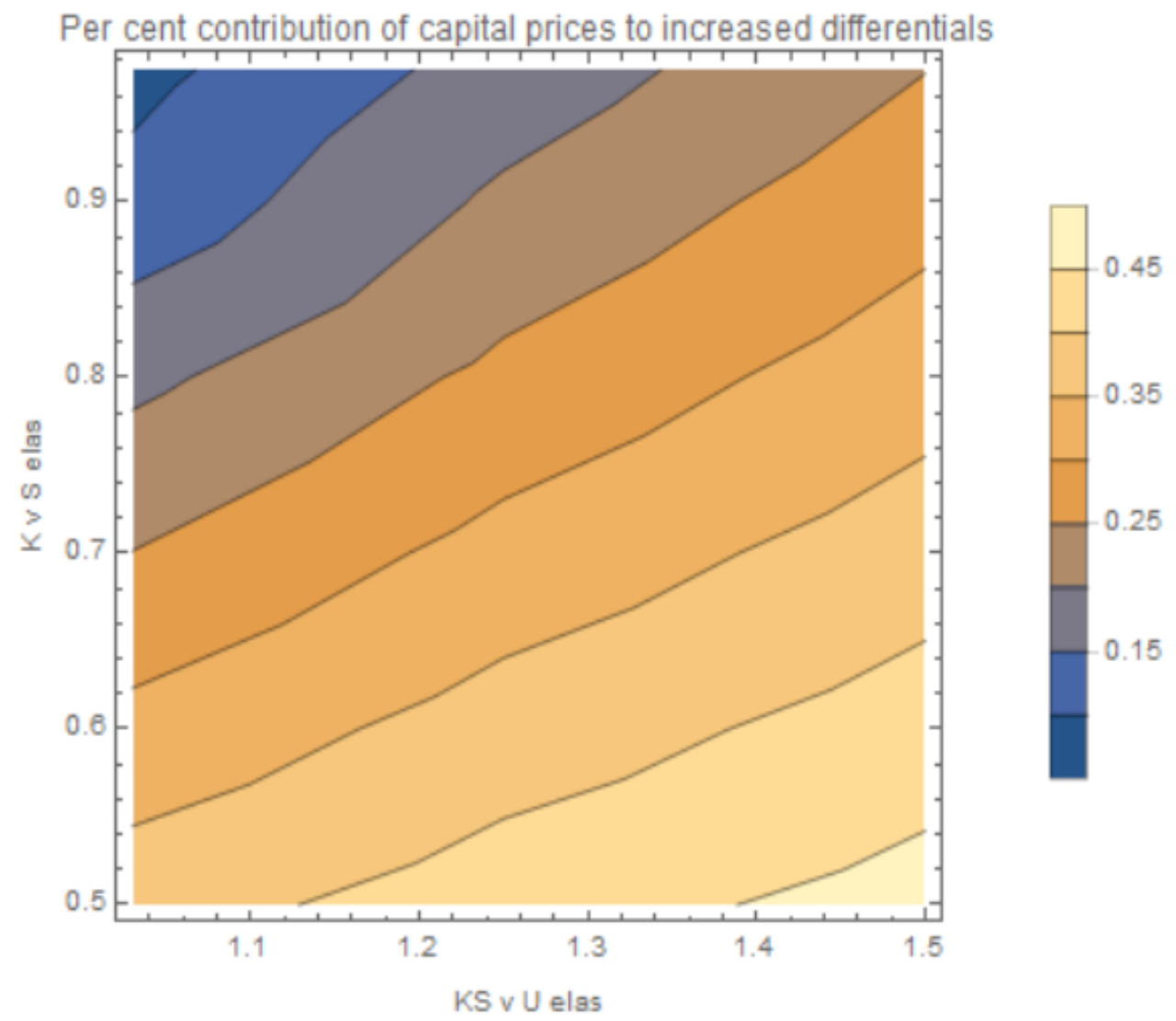

Figure 8: Contribution of capital prices to wage differentials, as a function of production side elasticities

supply of skilled labour, which is also not much affected by what combination of factor substitution elasticities we assume.

\section{Conclusions}

We set up a double-calibrated CGE model of the UK economy to decompose the increase in the skill premium according to its major major contributory factors, including the growing supply of skilled labour, technical change, international trade, and consumer preferences. We focus on the 1979 to 2000 period during which the UK economy went through rapid structural change along with globalization. This was indeed the period when wage inequality rose most sharply in the UK (unlike in other countries). We focus on one dimension of growing inequality that is easy to operationalize in a CGE model: the skilled wage premium. Thus our numerical analysis is subject to all the usual caveats concerning model structure, elasticity assumptions, and data availability. 


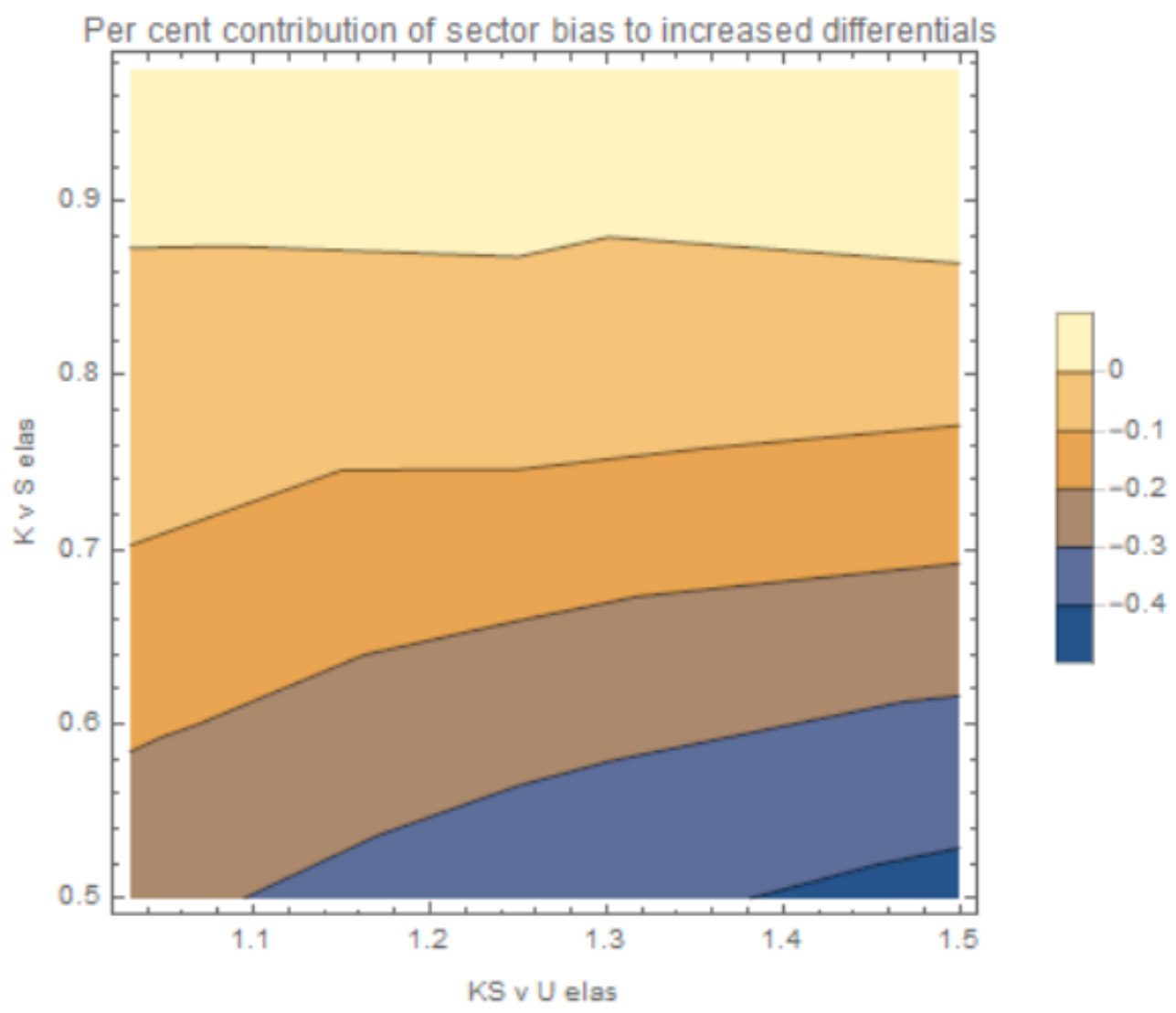

Figure 9: Contribution of capital prices to wage differentials, as a function of production side elasticities

While our model contains many of the elements examined in previous, single-equation studies, it has been designed to examine these potential causal factors simultaneously, in a way which is more robust than singleequation methods. At the same time, the model has been kept relatively simplified, to avoid becoming unnecessarily black-box in style. Importantly, the use of double calibration is important: when output, factor demands and intermediate inputs depend upon a combination of price and technological parameters (as well as on trade costs which are not directly observed but can be inferred following Anderson and Van Wincoop (2004)), then it is most sensible to ensure that the combination of parameter shifts assumed is consistent with the observed changes, before attempting decomposition. Hence, for example, world prices appear to have moved slightly in favour of unskilled workers, yet the import share of unskilled goods has moved in the opposite direction implying that there has been a reduction in border costs, which are not included in world traded prices. The rise in skilled/unskilled input ratios within industries has to be assessed simultaneously with the changes in factor prices, and with the change in capital input prices. Our double calibrated approach does this. 


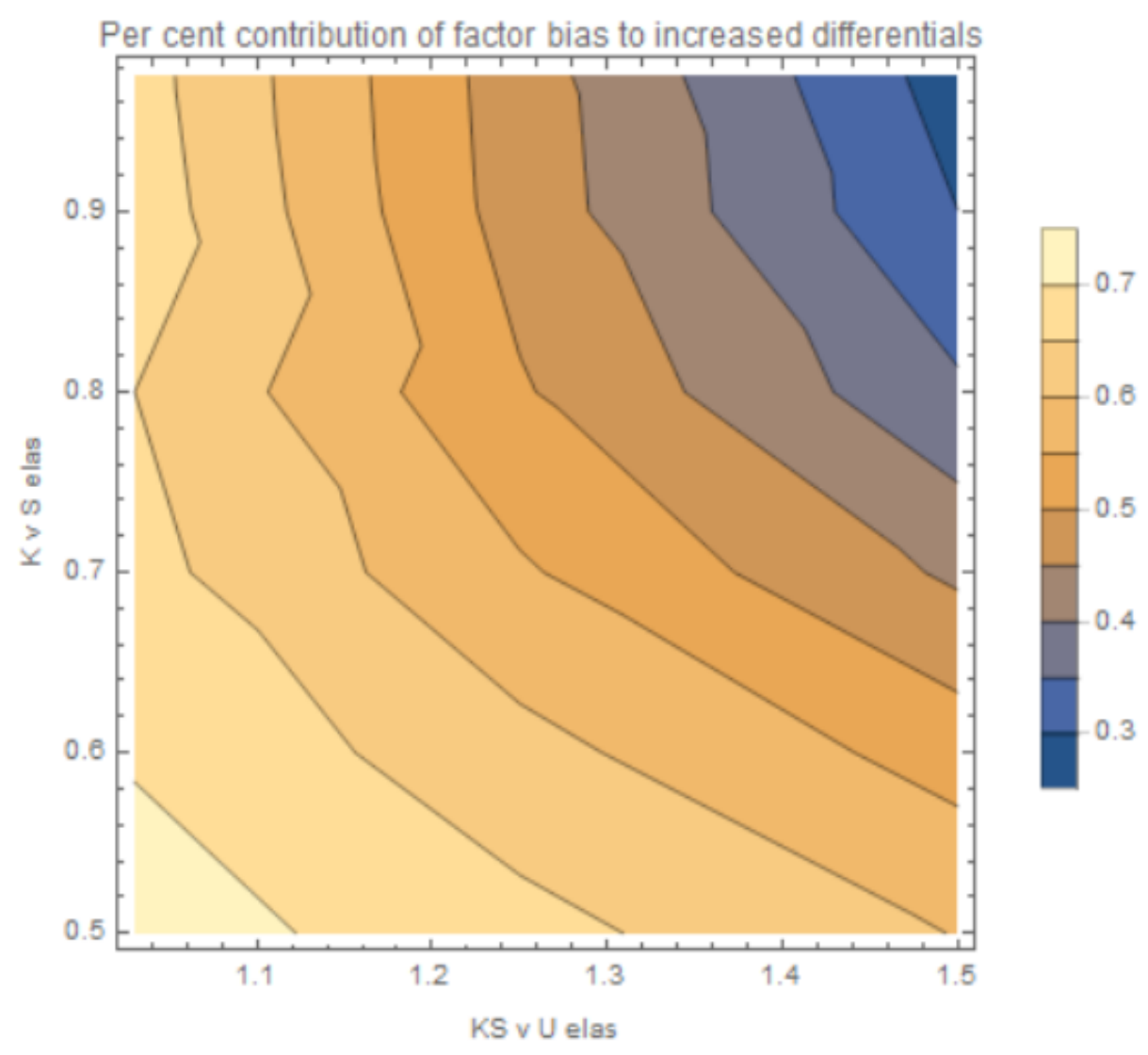

Figure 10: Contribution of capital prices to wage differentials, as a function of production side elasticities

In addition, our approach underlines the scepticism of survey articles (Chusseau et al., 2008; Kurokawa, 2014) about the appropriateness of a 'find the culprit' approach to decomposition, much though that approach may have dominated the debate in the early years. There are a number of aspects to this, which we seek to emphasise. First, the relatively small observed change in inequality is the net effect of large changes in contributory factors in opposing directions. While some of the previous productivity-skills analyses have taken this on board (Acemoglu, 2002; Autor et al., 2014, 2017), and the Autor papers), models which have focused on the trade and wages debate have not done so. This may be partly because, in the Stolper-Samuelson theorem, wages within the cone of diversification are determined mainly by traded prices, but this result breaks down once an Armington trade specification and/or factor fixity are introduced. Even modest departures from the HOS framework (Abrego and Whalley, 2003; Edwards and Whalley, 2007) lead us into a hybrid model, where both price effects and factor content vs labour supply effects are present. Our somewhat larger model here confirms this. Indeed it does more: by utilising an approach where a structural model is calibrated simultaneously 
on all prices and all volumes, we are able to investigate the senstivity to trade elasticity assumptions - a key point of dissent between labour market based studies such as Katz and Murphy (1992), Autor et al. (2014) or Acemoglu (2002) and trade price based explanations such as Haskel and Slaughter (2002) - and we are able to show that, once we constrain the combined effect of trade prices and sector bias has to be consistent with observed changes in trade volumes, the combined 'trade plus sector bias' effect is outweighed by factor bias and capital cheapening, albeit it is not negligible. In other words, once data on prices and volumes are included simultaneously, it is the data, rather than the assumed trade elasticity, which drives the results.

Indeed, our simulations indicate that several contributory factors on their own would have had a larger effect on the skill premium than the total observed 'net' increase. These include, in particular, a large rise in the supply of skilled labour (i.e. white-collar as opposed to blue-collar workers) that would have reduced the skill premium sharply, ceteris paribus. This potential effect is largely offset by the factor bias of technical change in favor of skilled labour that would have raised the skill premium in the absence of more skilled (i.e. white collar) workers. Furthermore, if one assumes that the production technology is dominated by capitalskill complementarity, then the observed fall in capital prices has pushed up the skill premium, whereas the sector bias of technical progress in favour of unskilled-labour-intensive sectors has reduced it. While in all our simulation, changes in international trade patterns and consumer preferences have a smaller effect upon the skill premium compared to factor biased technology, this effect is not small relative to the overall net change in the premium. Hence, while one cannot say 'trade was responsible for the rise', it can be seen as helping tip the balance quite significantly.

Second, our approach accepts that the contributory factors in our decomposition analysis are not independent of one another and hence are not fully exogenous in an economic sense. Hence, at least some of the change in skilled and unskilled inputs is as a result of skilled and unskilled wage changes and, if one accepts the capitalskill complementarity hypothesis (we view the evidence as mixed but on balance supporting it), partly down to a cheapening in the cost of investment. In the same vein, some at least of the increase in intermediate input use (and of imports within that) reflects the fall in border costs on unskilled-intensive inputs. Hence, our model does allow for an effect of trade via outsourcing.

Of course, there is no unique answer in decomposition analysis to what should be considered exogenous and what is endogenous. In particular, while some of the shift in factor input ratios may reflect prices, our model attributes some at least to shifts in factor share parameters in the production function ('factor bias'), which we treat as exogenous. There is a credible argument, following Acemoglu (2002) that even these changes may be endogenous, although we would argue that these shifts in technology may be determined more on a global level than in the UK (and hence may be partly responding to relative wage changes in other countries).

The interpretation of capital-skill complementarity is again a tricky one. It is quite conceivable that higher investment in the UK since 1979 simply led to an updating of the capital stock (and so the observed capital-skill complementarity is primarily a reflection of a long-term bias in favour of skilled labour, which is embodied 
when the capital stock is updated).

In addition, the long-term improvement in educational standards among the working-age population may well be considered a secular, policy-driven trend (and hence exogenous, for some purposes). However, the increase in the number of while-collar relative to blue-collar workers - our proxy for the rising supply of skilled labour - is clearly driven by economic variables such as the demand for particular skills and also the educational investments made by future workers.

Third, while this narrative does not represent a set of "hard" conclusions, it provides a structural view of how technological change emerges through cheaper machinery and is transmitted into the share parameters of sectoral production functions, resulting in factor and sector biasses. Our simulation model also nests, in a theoretically consistent manner, the main drivers of the growth in the skill premium that have been discussed in the literature. This structural view complements the many reduced-form approaches in the literature that permit econometric estimation but inevitably take a highly stylized view of what determines the skill premium.

Regarding the role of trade in particular in raising inequality, our extensive sensitivity tests for a wide range of trade elastiticities and alternative assumptions about inter-sectoral factor mobility demonstrate that our double-calibrated CGE model is stable with respect to Armington elasticities and labour mobility. Even when we vary the production technology all the way from Cobb-Douglas to a pronounced version of capital-skillcomplementarity, the simulation results change only in limited and entirely plausible ways. The stability of our model stands out in contrast to numerous studies that have appealed to general equilibrium to explain rising wage inequality, both trade-derived (Heckscher-Ohlin-Samuelson, or Armington, or Ricardo-Viner) and others such as factor content models: When general equilibrium models are fully laid out and calibrated, the overwhelming conclusion is that many of these models are unstable. By contrast, our model considers a wider range of explanatory factors, whose relative contributions are fairly stable across a range of parameter assumptions. ${ }^{16}$ In an HOS model, decomposition exercises also become problematic because small changes in explanatory variables lead to large changes in inequality. However, this is implausible because wage inequality has changed far more modestly over time (i.e. back a century or more) than most counterfactuals on these models would indicate.

Future research on the causes of growing skill-based wage inequality could usefully begin by asking why wage differentials increased only modestly, given the large potential effects of the opposing forces that act upon them. One possible approach, given the length of time periods covered, is to endogenize education and skill formation and also to look more close at expectation formation and related policy in the context of a fully dynamic model.

\footnotetext{
${ }^{16}$ Also worrying is the contrast between the (unstable) factor-contents approach of labour economists and the (equally unstable but in different ways) Heckscher-Ohlin model of many trade theorists. In the former, factor-biased technology and changing factor endowments produce huge effects on relative wages for plausible values of the various elasticities; in the latter, the factor bias of technical change or endowments have no effect, but the sector bias of technical change and traded goods prices have magnified - in practice, enormous - effects. Moreover, as Abrego and Whalley (2003) and Edwards and Whalley (2007) have pointed out, these conclusions of the HOS model are not, in practice, robust to even small changes in model structure.
} 


\section{References}

Abrego, L. and Whalley, J. (2003). Goods market responses to trade shocks and trade and wages decompositions. Canadian Journal of Economics/Revue Canadienne d'Economique.

Acemoglu, D. (2002). Technical change, inequality, and the labor market. Journal of Economic Literature, 40(1):7-72.

Anderson, J. E. and van Wincoop, E. (2004). Trade Costs. Journal of Economic Literature, 42(3):691-751.

Anderson, J. E. and Van Wincoop, E. (2004). Trade Costs. Technical report.

Anderton, B. and Brenton, P. (1999). Outsourcing and Low-Skilled Workers in the UK. Bulletin of Economic Research, 51(4):267-285.

Atolia, M. and Kurokawa, Y. (2016). The impact of trade margins on the skill premium: Evidence from Mexico. Journal of Policy Modeling, 38(5):895-915.

Autor, D., Dorn, D., Katz, L. F., Patterson, C., and Reenen, J. V. (2017). Concentrating on the Fall of the Labor Share. American Economic Review, 107(5):180-185.

Autor, D. H. and Dorn, D. (2013). The Growth of Low-Skill Service Jobs and the Polarization of the US Labor Market. American Economic Review, 103(5):1553-1597.

Autor, D. H., Dorn, D., Hanson, G. H., and Song, J. (2014). Trade Adjustment: Worker-Level Evidence. The Quarterly Journal of Economics, 129(4):1799-1860.

Bakhshi, H. and Thompson, J. (2002). Explaining trends in UK business investment. Bank of England Quarterly Bulletin.

Baldwin, R. E. and Cain, G. (2000). Shifts in US Relative Wages: The Role of Trade. Review of Economics and Statistics, 49(1):580-595.

Baumann, U. and Price, S. (2007). Understanding investment better: insights from recent research. Bank of England Quarterly Bulletin.

Becker, S. O., Fetzer, T., and Novy, D. (2016). Who Voted for Brexit? A Comprehensive District-Level Analysis. CAGE Online Working Paper Series, Warwick, no 317.

Bontout, O. and Jean, S. (2000). What Drove Relative Wages in France? Structural Decomposition Analysis in a General Equilibrium Framework, 1970-1992. Working Papers 2000-03, CEPII research center.

Borjas, G., Freeman, R., and Katz, L. (1992). On the Labor Market Implications of Immigration and Trade. Immigration and the Work Force, by G.J. Borjas and R.B. Freeman (eds), U Chicago Press, pages 213-244. 
Burstein, A. and Vogel, J. (2017). International Trade, Technology, and the Skill Premium. Journal of Political Economy, 125(5):1356-1412.

Chusseau, N., Dumont, M., and Hellier, J. (2008). Explaining Rising Inequality: Skill-Biased Technical Change And North-South Trade . Journal of Economic Surveys, 22(3):409-457.

Correa, J. A., Lorca, M., and Parro, F. (2017). Capital-skill complementarity: Does capital composition matter? The Scandinavian Journal of Economics.

Costinot, A. and Vogel, J. (2015). Beyond Ricardo: Assignment Models in International Trade. Annual Review of Economics, 7(1):31-62.

Dawkins, C., Srinavasan, T., and Whalley, J. (2001). Calibration. Handbook of Econometrics, Elsevier, by J.J.Heckman and E.E.Leamer (eds). Edition 1 vol 5.

DeSantis, R. A. (2003). Wage Inequality in the United Kingdom: Trade and/or Technology? The World Economy, 26(6):893-909.

Eaton, J. and Kortum, S. (2001). Technology, trade, and growth: A unified framework. European Economic Review, 45(4-6):742-755.

Edwards, T. and Perroni, C. (2014). Market Integration, Wage Concentration, and the Cost and Volume of Traded Machines. CESifo Working Paper Series no 4997.

Edwards, T. H. and Whalley, J. (2007). Short- and long-run decompositions of UK wage inequality changes. Bulletin of Economic Research.

Feenstra, R. C. and Hanson, G. H. (1996). American Economic Association Globalization, Outsourcing, and Wage Inequality. Source: The American Economic Review, 86(2):240-245.

Fouquin, M. and Hugot, J. (2016). Back to the future: International trade costs and the two globalizations. Working Papers 2016-13, CEPII.

Goos, M. and Manning, A. (2007). Lousy and Lovely Jobs: The Rising Polarization of Work in Britain. The Review of Economics and Statistics, 89(1):118-133.

Greenaway, D., Upward, R., and Wright, P. (2000). Sectoral transformation and labour-market flows. Oxford Review of Economic Policy, 16(3):57-75.

Griliches, Z. (1969). Capital-Skill Complementarity. Review of Economics and Statistics, Notes, 51:465-468.

Grossman, G., Helpman, E., Oberfield, E., and Sampson, T. (2017). The Productivity Slowdown and the Declining Labor Share: A Neoclassical Exploration. 
Harrigan, J. and Balaban, R. (1999). U.S. Wages in General Equilibrium: The Effects of Prices, Technology, and Factor Supplies, 1963-1991. NBER Working Papers 6981, National Bureau of Economic Research, Inc.

Harrigan, J. and Reshef, A. (2015). Skill-biased heterogeneous firms, trade liberalization and the skill premium. Canadian Journal of Economics, 48(3):1024-1066.

Haskel, J. and Slaughter, M. J. (2001). Trade, Technology and U.K. Wage Inequality. Economic Journal, 111(468):163-187.

Haskel, J. E. and Slaughter, M. J. (2002). Does the sector bias of skill-biased technical change explain changing skill premia? European Economic Review.

Hillberry, R. H., Anderson, M. A., Balistreri, E. J., and Fox, A. K. (2005). Taste parameters as model residuals: Assessing the "fit" of an Armington trade model. Review of International Economics.

Jones, R. W. (1965). The structure of simple general equilibrium models. Journal of Political Economy, 73(6):557-572.

Jones, R. W. (2000). Technical progress, price adjustments, and wages. Review of International Economics, 8(3):497-503.

Karabarbounis, L. and Neiman, B. (2014). The global decline of the labor share. The Quarterly Journal of Economics, 129(1):61-103.

Katz, L. F. and Murphy, K. M. (1992). Changes in Relative Wages, 1963-1987: Supply and Demand Factors, volume 107.

Krugman, P. R. (2008). Trade and Wages, Reconsidered. Brookings Papers on Economic Activity, 39(1 (Spring):103-154.

Krusell, P., Ohanian, L. E., RÌos-Rull, J.-V., and Violante, G. L. (2000). Capital-Skill Complementarity and Inequality: A Macroeconomic Analysis. Econometrica, 68(5):1029-1054.

Kurokawa, Y. (2014). A Survey Of Trade And Wage Inequality: Anomalies, Resolutions And New Trends. Journal of Economic Surveys, 28(1):169-193.

Lawrence, R. Z. (2015). Recent Declines in Labor's Share in US Income: A Preliminary Neoclassical Account. NBER Working Papers 21296, National Bureau of Economic Research, Inc.

Lawrence, R. Z. and Slaughter, M. J. (1993). International Trade and American Wages in the 1980s: giant sucking sound or small hiccup? Technical report. 
Leamer, E. (1998a). Global integration and wages in a general equilibrium world model: contributions in World Scan. In Global Trade and European Workers, Brenton, P, and J.Pelkmans (eds), pages 123-146.

Leamer, E. (1998b). In search of Stolper-Samuelson linkages between international trade and lower wages . In Imports, Exports and the American Worker, by S Collins.

León-Ledesma, M. A., McAdam, P., and Willman, A. (2010). Identifying the Elasticity of Substitution with Biased Technical Change. American Economic Review, 100(4):1330-1357.

Lücke, M. (1997). European trade with lower-income countries and the relative wages of the unskilled: an exploratory analysis for West Germany and the UK. Kiel Working Papers no 819.

Murphy, K. and F.Welch (1989). Wage Premiums for College Graduates: Recent growth and possible explanations. Educational Researcher, 18:17-26.

Neary, J. P. (1978). Short-Run Capital Specificity and the Pure Theory of International Trade. Source: The Economic Journal, 88(351):488-510.

Neven, D. and Wyplosz, C. (1996). Relative prices, trade and restructuring in european industry. CEPR Discussion Papers, (1451).

Oberfield, E. and Raval, D. (2012). Micro Data and the Macro Elasticity of Substitution. Working Papers 12-05, Center for Economic Studies, U.S. Census Bureau.

Okushima, S. and Tamura, M. (2009). A double calibration approach to the estimation of technological change. Journal of Policy Modeling.

Pavcnik, N. (2002). Trade liberalization, exit, and productivity improvements: Evidence from Chilean plants. Review of Economic Studies.

Sampson, T. (2014). American Economic Journal: Microeconomics, 6(3).

Smith, J. (2008). That elusive elasticity and the ubiquitous bias: is panel data a panacea? . Bank of England Working Paper 342.

Stolper, W. F. and Samuelson, P. A. (1941). Protection and Real Wages. The Review of Economic Studies.

Winchester, N. and Greenaway, D. (2007). Rising wage inequality and capital-skill complementarity. Journal of Policy Modeling.

Wood, A. (1994). North South Trade, Employment and Inequality. Oxford University Press.

Wood, A. (2018). The 1990s trade and wages debate in retrospect. The World Economy, (02). 


\section{Appendix Basic CGE model for the decomposition analysis: listing of sets}

g goods /M,E,N,F/;

of which a subset is i industry /M,E,F/;

ii has the same members as $\mathbf{i}$ (but is transposed).

c country /'Home', 'Advanced', 'Developing'/; of which there is a subset cf foreign country /'Advanced', 'Developing'/;

n nation /'UK'/;

\section{Variable listing}

$Y_{n, i}$ output by industry,

$L U_{n, i}$ unskilled labour by industry,

$L S_{n, i}$ skilled labour by industry,

$K_{n, i}$ capital stock by industry,

$K S_{n, i}$ capital skill aggregate by industry,

$P K S_{n, i}$ price of capital skill aggregate,

$V A_{n, i}$ value added by industry,

$P V_{n, i}$ price of value added,

$I M E D_{n, i i, i}$ intermediate input,

$P Y_{n, i}$ output price,

$W U_{n, i}$ unskilled wage,

$W S_{n}$ skilled wage,

$K R_{n, i}$ capital rental,

$P K_{n}$ price of capital goods,

$P A_{n, i}$ price of Armington aggregate,

$P F_{i, c, i}$ foreign goods price,

$P W T_{n, i}$ world trade price,

$X V O L_{n, i}$ export volume,

$E X_{n, i}$ export value,

$T U_{n, i}$ total volume use,

$M V O L_{n, c, i}$ import or use volume,

$I M_{n, c, i}$ import or use value,

$I N C_{n}$ income of domestic consumers,

$C O N_{n}$ total consumer expenditure,

$C V_{n, i}$ consumption value,

$C_{n, i}$ consumption volume,

$I N V_{n}$ investment volume, 
$K I_{n, i}$ input value into capital goods industry,

$K_{n, i}$ input volume into capital goods industry;

$L U S_{n}$ total unskilled labour force.

$L S S_{n}$ total skilled labour force.

$\triangle W_{n}$ unskilled wage differential between sectors;

$B O P_{n}$ balance of payments value.

\section{Parameter listing.}

$\alpha \bar{k} s$ scale parameter for capital-skill aggregate.

$\bar{\beta} u_{n, i}$ unskilled share parameter.

$\beta \bar{k} s_{n, i}$ capital-skill share parameter in value added.

$\bar{\beta} s_{n, i}$ skill share parameter in capital-skill aggregate.

$\beta \bar{k} g_{n, i}$ capital share parameter in capital-skill aggregate.

$\alpha \overline{o p}_{n, i}$ top-level scale parameter.

$\bar{\theta} i_{n, i i, i}$ intermediates share in output.

$\alpha w \bar{t}_{n, i}$ scale parameter for trade shares aggregation.

$\beta \bar{w} t_{n, c, i}$ share parameters for each of $\mathrm{c}$ in trade.

$\beta \overline{u s e}_{n, c, i}$ shares of each country's produce in use.

$\alpha \bar{u} s e_{n, i}^{\frac{\rho a \bar{e} m}{1-\rho \bar{e} m}}$ scale parameter for aggregation of use from each c.

$\gamma \overline{c o} n_{n, i}$ Cobb-Douglas share of each good in consumption spoending.

$\phi \bar{k} g_{n, i}$ shares of each good in capital spending.

$r_{n}$ interest rate.

$\bar{\delta}$ depreciation rate.

$G K_{n}$ average growth rate of capital stock.

\section{Elasticities listing.}

$\sigma \bar{k} s$ elasticity of substitution between capital and skill.

$\sigma \bar{t}$ opelasticity of substitution between ks and $\mathrm{u}$.

$\sigma a \bar{r} m$ armington elasticity of substitution in trade.

$\rho \bar{k} s=\frac{\sigma \bar{k} s-1}{\sigma \bar{k} s}$.

$\rho \overline{t o p}=\frac{\sigma \overline{t o p}-1}{\sigma \overline{t o p}}$.

$\rho a \bar{r} m=\frac{\sigma a \bar{r} m-1}{\sigma a \bar{r} m}$.

\section{Equation listing.}

Output of each industry

Gross output of each industry is related to value added by a ratio. 


$$
Y_{n, i}=\frac{V A_{n, i}}{\alpha \bar{v}_{n, i}}
$$

Value added of each industry

Value added of each industry is a CES combination of a capital-skill aggregate and unskilled labour:

$$
V A_{n, i}=\alpha t \overline{o p}{ }_{n, i} \cdot\left(\beta \bar{k} s_{n, i} \cdot K S_{n, i}^{\rho \overline{t o p}}+\bar{\beta} u_{n, i} \cdot L U_{n, i}^{\rho \overline{t o p}}\right)^{\frac{1}{\rho t o p}}
$$

Price of value added of each industry

$$
P V_{n, i} \cdot V A_{n, i}=K S_{n, i} . P K S_{n, i}+W U_{n, i} \cdot L U_{n, i} .
$$

\section{Capital/skill complementarity}

Capital stock and skilled labour are combined to make a CES Capital/skill aggregate

$$
K S_{n, i}=\alpha \bar{k} s_{n, i} \cdot\left(\bar{\beta} s_{n, i} \cdot L S_{n, i}^{\rho \bar{k} s}+\beta \bar{k} g_{n, i} \cdot K_{n, i}^{\rho \bar{k} s}\right)^{\frac{1}{\rho k s}} .
$$

Price of capital-skill aggregate

$$
K S_{n, i} \cdot P K S_{n, i}=K R_{n, i} \cdot K_{n, i}+W S_{n} \cdot L S_{n, i} .
$$

Skilled labour input of each industry

$$
L S_{n, i}=K S_{n, i} \cdot P K S_{n, i}^{\frac{1}{1-\rho \bar{k} s}} \cdot \alpha \bar{k} s_{n, i}^{\frac{\rho \bar{k} s}{1-\rho k s}} \cdot\left(\frac{\bar{\beta} s_{n, i}}{W S_{n}}\right)^{\frac{1}{1-\rho k s}} .
$$

Capital stock of each industry

$$
K_{n, i}=K S_{n, i} \cdot P K S_{n, i}^{\frac{1}{1-\rho \bar{k} s}} \cdot \alpha \bar{k} s_{n, i}^{\frac{\rho \bar{k} s}{1-\rho \bar{k} s}} \cdot\left(\frac{\beta \bar{k} g_{n, i}}{K R_{n, i}}\right)^{\frac{1}{1-\rho k s}}
$$

\section{Unskilled labour}

Unskilled labour input of each industry is related to value added and the unskilled wage relative to the price of value added

$$
L U_{n, i}=V A_{n, i} \cdot P V_{n, i}^{\overline{1-\rho t o p}} * . \alpha t \overline{o p}, i, \cdot\left(\frac{\beta \bar{u}_{n, i}}{\beta \bar{u}_{n, i}}\right)^{\frac{1}{1-\rho t o p}}
$$

\section{Intermediate inputs}

Intermediate inputs derived from share of total gross output 


$$
\operatorname{IME} D_{n, i i, i}=\bar{\theta} i_{n, i i, i} . Y_{n, i} .
$$

\section{Price of gross output}

Price of output of each industry

$$
P Y_{n, i} \cdot Y_{n, i}=V A_{n, i} . P V_{n, i}+\sum_{i i}\left(I M E D_{n, i i, i} \cdot P A_{n, i i}\right) ;
$$

Price of capital goods

$$
P K_{n} . I N V_{n}=\sum_{i}\left(K I_{n, i}\right)
$$

\section{Armington aggregation}

Armington aggregate price

$$
P A_{n, i}=\sum_{c}\left(\frac{M V O L_{n, c, i} . P F_{n, c, i}}{T U_{n, i}}\right) .
$$

World trade price

$$
P W T_{n, i}=\frac{1}{\alpha \bar{w} \bar{t}_{n, i}} \cdot\left(\beta \bar{w} t_{n, h \text { home }}^{\frac{1}{1-\rho a \bar{e} m}} \cdot P Y_{n, i}^{\frac{\rho a \bar{e} m}{\rho a e m-1}}+\sum_{c \neq^{\prime} h o m e^{\prime}}\left(\beta w t_{n, c, i}^{\frac{1}{1-\rho a \bar{m} m}} \cdot P F_{n, c, i}^{\frac{\rho a \bar{e} m}{\rho a e \bar{m}-1}}\right)\right)^{\frac{\rho a e \bar{m}-1}{\rho a \bar{e} m}}
$$

\section{Exports}

Exports volume

$$
X V O L_{n, i}=W T_{n, i}(N, I) \cdot P W T_{n, i}^{\frac{1}{1-\rho a \bar{e} m}} \cdot \alpha \bar{w} t_{n, i}^{\frac{\rho a \bar{e} m}{1-\rho \bar{e} m}} \cdot\left(\frac{\beta \bar{w} t_{n,,^{\prime} h o m e^{\prime}, i}}{P Y_{n, i}}\right)^{\frac{1}{1-\rho \bar{e} m}} .
$$

Exports value

$$
E X_{n, i}=X V O L_{n, i} . P Y_{n, i}
$$

\section{Imports}

Imports volume

$$
M V O L_{n, c, i}=T U_{n, i} \cdot P A_{n, i}^{\frac{1}{1-\rho a \bar{e} m}} \cdot \alpha \bar{u} s e_{n, i}^{\frac{\rho a \bar{e} m}{1-\rho \bar{e} m}} \cdot\left(\frac{\beta \bar{u} s e_{n, c, i}}{P F_{n, c, i}}\right)^{\frac{1}{1-\rho a \bar{e} m}} .
$$

Imports value 


$$
I M_{n, c, i}=M V O L_{n, c, i} . P F_{i, c, i}
$$

Income

$$
I N C_{n}=\sum_{i}\left(W U_{n, i} . L U_{n, i}\right)+W S_{n} . L S S_{n}+\sum_{i}\left(K R_{n, i} . K_{n, i}\right) .
$$

Incomes and consumption

Total value of consumption

$$
C O N_{n}=I N C_{n}-I_{n} \cdot P K_{n}(N)-B O P_{n} .
$$

Total value of consumption

$$
C V_{n, i}=C O N_{n} \cdot \gamma \overline{c o} n_{n, i}
$$

Total volume of consumption

$$
C_{n, i}=\frac{C V_{n, i}}{P A_{n, i}}
$$

Investment

Investment volume

$$
I_{n}=\sum_{i}\left(\left(G K_{n}+\bar{\delta}\right) \cdot K_{n, i}\right.
$$

Capital input value

$$
K I_{n, i}=P A_{n, i} . K_{n, i} .
$$

Capital input volume

$$
K_{n, i}=I_{n} \cdot \phi \bar{k} g_{n, i} .
$$

\section{Total use}

Volume of total use

$$
T U_{n, i}=C_{n, i}+K_{n, i}+\sum_{i i}\left(I M E D_{n, i, i i}\right) .
$$




\section{Labour markets clearance}

Unskilled labour market clearance

$$
\sum_{i} L U_{n, i}=L U S_{n}
$$

Skilled labour market clearance.

$$
\sum_{i} L S_{n, i}=L S S_{n}
$$

Unskilled labour market mobility costs

Unskilled wage in contracting sector

$$
W U_{n, m^{\prime}}=W U_{n,^{\prime} e^{\prime}}-\triangle W
$$

Unskilled wage sectoral difference (adjustment equation)

$$
\triangle W=\triangle W_{0} \cdot \frac{\left(\left(L U_{0 n, m^{\prime} m^{\prime}}-L U_{n,^{\prime} m^{\prime}}\right)-\left(L U_{0 n, e^{\prime}}-L U_{n,{ }^{\prime} e^{\prime}}\right)\right)}{\left(\left(L U_{0 n,{ }^{\prime} m^{\prime}}-L U_{1 n,{ }^{\prime} m^{\prime}}\right)-\left(L U_{0 n, e^{\prime} e^{\prime}}-L U_{1 n,{ }^{\prime} e^{\prime}}\right)\right)} .
$$

Capital return

$$
K R_{n, i}=P K_{n}\left(r_{n}+\bar{\delta}\right) .
$$

Home economy balance

$$
M V O L_{n,{ }^{\prime} h o m e^{\prime}, i}=Y_{n, i}-E X V O L_{n, i} .
$$

External balance

$$
B O P_{n}=B O P_{0 n}
$$

OBJ_E.. OBJ_V =E= 0 ; 


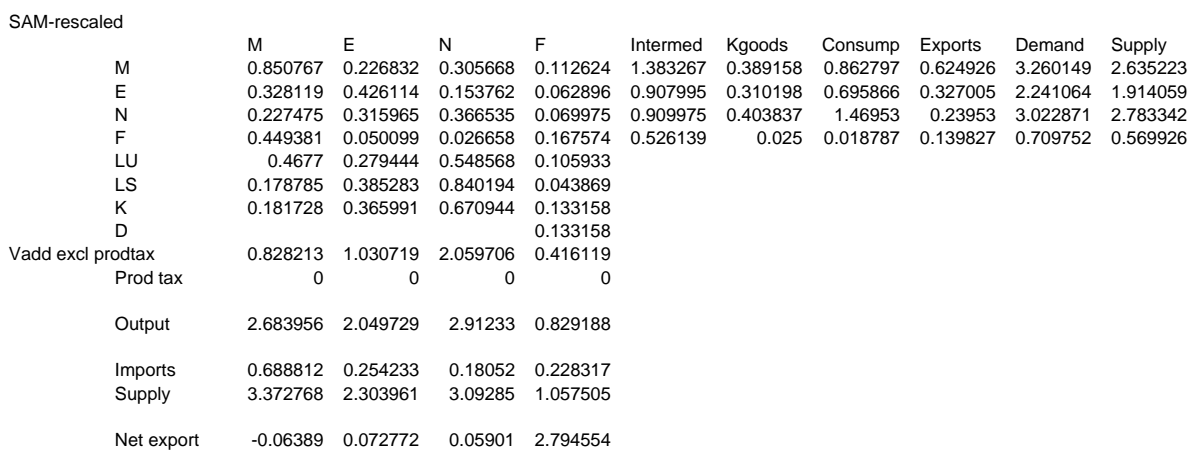

Simplified SAM for the UK model, 1979. Derived from OECD.

Figure 11 


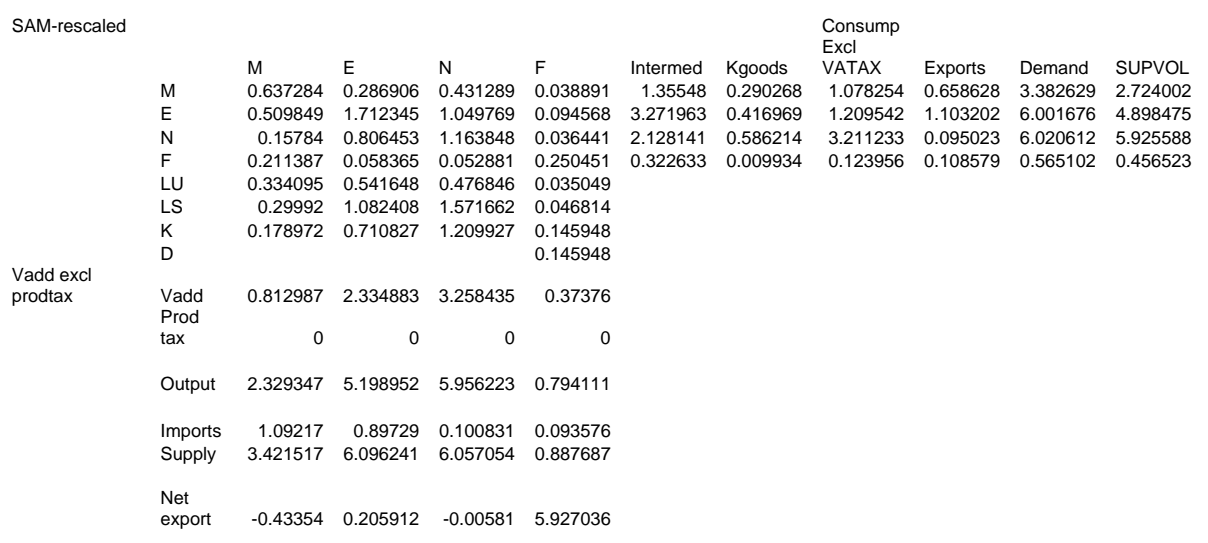

Simplified SAM for the UK 2000, derived from OECD

Figure 12 